\title{
Phosphoinositide Phosphatases in Cell Biology and Disease
}

\author{
Yang Liu and Vytas A. Bankaitis* \\ Department of Cell \& Developmental Biology, Lineberger Comprehensive Cancer Center, University \\ of North Carolina School of Medicine, Chapel Hill, North Carolina 27599-7090, USA
}

\section{Abstract}

Phosphoinositides are essential signaling molecules linked to a diverse array of cellular processes in eukaryotic cells. The metabolic interconversions of these phospholipids are subject to exquisite spatial and temporal regulation executed by arrays of phosphatidylinositol (PtdIns) and phosphoinositide-metabolizing enzymes. These include PtdIns- and phosphoinositide-kinases that drive phosphoinositide synthesis, and phospholipases and phosphatases that regulate phosphoinositide degradation. In the past decade, phosphoinositide phosphatases have emerged as topics of particular interest. This interest is driven by the recent appreciation that these enzymes represent primary mechanisms for phosphoinositide degradation, and because of their everincreasing connections with human diseases. Herein, we review the biochemical properties of six major phosphoinositide phosphatases, the functional involvements of these enzymes in regulating phosphoinositide metabolism, the pathologies that arise from functional derangements of individual phosphatases, and recent ideas concerning the involvements of phosphoinositide phosphatases in membrane traffic control.

\section{Introduction}

Phosphoinositides are phosphorylated derivatives of PtdIns (Fig. 1), and these lipid species represent quantitatively minor components of cell membranes. In eukaryotic cells, PtdIns generally constitutes less than $10 \%$ of the total cellular phospholipid with Phosphoinositides usually comprise only several percent of total cellular inositol lipids (Rameh et al., 1997;Fruman et al., 1998;Martin, 1998;Di Paolo and De Camilli, 2006). However, in spite of their low abundance, phosphoinositides regulate a host of fundamental cellular processes. These include signal transduction, intracellular membrane trafficking, cytoskeleton remodeling, nuclear events, control of cell growth and survival, etc. This functional diversity of function in part reflects the molecular diversity of these compounds. Mammalian cells produce seven chemically distinct, but interconvertible, phosphoinositide species: phosphatidylinositol 3-phosphate (PtdIns-3-P), PtdIns-4-P, PtdIns-5-P, phosphatidylinositol 3,5-bisphosphate (PtdIns-3,5- $\mathrm{P}_{2}$ ), PtdIns-4,5- $\mathrm{P}_{2}$, PtdIns-3,4- $\mathrm{P}_{2}$, and phosphatidylinositol-3,4,5-trisphosphate (PtdIns-3,4,5-P 3 ) (Fig. 1). Phosphoinositides phosphorylated at the $3-\mathrm{OH}$ position are not substrates for phospholipases $\mathrm{C}$, so these phosphoinositides hold intrinsic signaling functions whose execution is not mediated through the action of derivative second messengers. It is through the action of phosphatases that 3-OH phosphoinositides are degraded.

(C) 2009 Elsevier Ltd. All rights reserved.

*corresponding author, TEL: 919-962-9870 FAX: 919-966-1856, vytas@med.unc.edu.

Publisher's Disclaimer: This is a PDF file of an unedited manuscript that has been accepted for publication. As a service to our customers we are providing this early version of the manuscript. The manuscript will undergo copyediting, typesetting, and review of the resulting proof before it is published in its final citable form. Please note that during the production process errors may be discovered which could affect the content, and all legal disclaimers that apply to the journal pertain. 
Yeast produce five phosphoinositide species (Fig. 2), and lack the capacity to generate the PtdIns-3,4- $\mathrm{P}_{2}$ and PtdIns-3,4,5- $\mathrm{P}_{3}$ species produced by mammals and other higher eukaryotes (Fig. 3). The 3-OH and 4-OH PtdIns-monophosphate species represent the major phosphoinositides in yeast, each constituting ca $1.5 \%$ of total inositol glycerophospholipid in this organism (ca. $0.3 \%$ of total glycerophospholipid). PtdIns-4,5- $\mathrm{P}_{2}$ is present at approximately half the mass of PtdIns-3-P or PtdIns-4-P. Basal PtdIns-3,5- $\mathrm{P}_{2}$ levels are vanishingly low, essentially at the level of detection, until yeast are subject to stress particularly hyperosmotic stress (Dove et al., 1997). Upon such challenge, PtdIns-3,5- $\mathrm{P}_{2}$ levels rise rapidly. The 4-OH phosphoinositides are all essential in yeast as evidenced by demonstrations that functional ablation of either one of the two major PtdIns 4-OH kinases (Pik1 and Stt4), or of the single PtdIns-4-P 5-OH kinase (Mss4), represent lethal events. Although 3-OH phosphoinositides play important homeostatic functions in yeast, these are essential for cell viability only under stress conditions (Schu et al., 1993;Fruman et al., 1998;Martin, 1998).

Of the total inositol lipid content in mammalian cells, approximately 5\% is invested in PtdIns-4$\mathrm{P}$ and PtdIns-4,5- $\mathrm{P}_{2}$, respectively - i.e. $0.5 \%$ of total cellular phospholipid in each case (Rameh and Cantley, 1999). These two 4-OH phosphorylated phosphoinositides represent by far the major phosphoinositide species in mammalian cells, constituting $90 \%$ of total cellular phosphoinositides (Roth, 2004; Di Paolo and De Camilli, 2006). By comparison, less than $0.25 \%$ of the total inositol phospholipid is phosphorylated on the D-3 position -- PtdIns-3-P

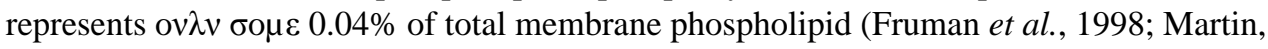
1998; Whisstock et al., 2002; Roth, 2004; Waselle et al., 2005; Di Paolo and De Camilli, 2006).

The chemically distinct phosphoinositide species each execute unique functions in cells, and the mono-phosphorylated phosphoinositides are not simple intermediates in production of the higher poly-phosphorylated species. Translation of chemical diversity to functional diversity is in part determined by preferred interface of individual phosphoinositide species with regulatory effector proteins that harbor phosphoinositide - binding domains. Examples include the pleckstrin homology $(\mathrm{PH})$ domains, phox homology (PX) domains, epsin N-terminal homology (ENTH) domains, band 4.1/ezrin/radixin/moesin (FERM) and Fab1p/YOTB/ Vac1p/EEA1 (FYVE) domains and lysine-arginine patches (Di Paolo and De Camilli, 2006; Lemmon, 2008).

All phosphoinositides are restricted to the cytosolic leaflets of intracellular membranes, and these are not homogeneously distributed in the membranes that contain them (Roth, 2004).

Moreover, the representation of individual phosphoinositide species varies between subcellular compartments and contributes to establishment and/or maintenance of organelle identity. For example, PtdIns-3-P is enriched on endocytic membranes, PtdIns-4-P on trans-Golgi (TGN) membranes, and PtdIns-4,5- $\mathrm{P}_{2}$ is localized primarily on the plasma membrane -- although Golgi pools are detected. PtdIns-3,5- $\mathrm{P}_{2}$ is most abundant in multivesicular bodies (MVBs) and late endosomes, on the yeast vacuole, and on mammalian lysosomes (Levine and Munro, 2002; De Matteis and Godi, 2004a; De Matteis and Godi, 2004b; Di Paolo and De Camilli, 2006). PtdIns-3,4,5- $\mathrm{P}_{3}$ is produced almost exclusively on the inner leaflet of the plasma membrane, although this most highly modified phosphoinositide might also accumulate on membranes of intracellular organelles and in the nuclear matrix following growth factor receptor activation (Ellson et al., 2001; Shisheva, 2001; Lee et al., 2002; van Rheenen and Jalink, 2002; Watt et al., 2002; Waselle et al., 2005).

Steady-state phosphoinositide distribution is the manifestation of a highly dynamic program of production and turnover executed by the enzymes that regulate phosphoinositide synthesis, interconversion, and degradation. Under basal conditions, phosphoinositide metabolism is 
tightly regulated by a set of specific kinases that are responsible for synthesis of phosphoinositides, and phosphatases that temporally and spatially catalyze phosphoinositide dephosphorylation. The yeast and mammalian phosphoinositide metabolic schemes are detailed in Fig. 2 and Fig. 3, respectively. In addition, under stimulated conditions, phospholipases $\mathrm{C}$ hydrolyze individual phosphoinositide species (excepting those phosphorylated on the $\mathrm{D} 3$ position) with the consequence of that a variety of soluble inositol phosphates are produced - each of which apparently manifest potent second messenger activities (Singer et al., 1997;Liscovitch et al., 2000;Rebecchi and Pentyala, 2000;Strahl and Thorner, 2007; Majerus et al., 1999).

The anabolic arm of phosphoinositide metabolism is governed by lipid kinases that transfer the $\gamma$-phosphate of ATP to the 3-OH, 4-OH or 5-OH position of the inositol ring. PtdIns kinases are conserved enzymes found throughout the Eukaryota, and these enzymes are classified into three major subgroups based on their positional specificities: PtdIns 3-OH kinases ( $\mathrm{PI}_{3} \mathrm{~K}_{\mathrm{s}}$ ), PtdIns 4-OH kinases (PI4Ks), and phosphoinositide-kinases (PIPKs) (Loijens et al., 1996; Zvelebil et al., 1996; Domin and Waterfield, 1997). The PI3Ks constitute a large family of enzymes responsible for production of PtdIns-3-P, PtdIns-3,4-P $\mathrm{P}_{2}$ and PtdIns-3, 4,5-P $\mathrm{P}_{3}$ (Fig. 2 and fig 3). PI4Ks and PtdIns 5-OH kinase (PI5K) convert PtdIns to PtdIns-4-P or PtdIns-5-P, respectively. We do note, however that while PI5K activity has been demonstrated in vitro, there is no available evidence to indicate that PtdIns-5-P is generated from PtdIns by such a reaction in vivo. Some mammalian enzymes also catalyze the higher order phosphorylation of PtdIns-5-P or PtdIns-4-P to PtdIns-4,5-P 2 (Fig. 3). Unlike most of the cognate mammalian PtdIns- and phosphoinositide-kinases, the yeast enzymes exhibit exquisite substrate specificities -- each kinase only phosphorylates a single inositol-phospholipid substrate. Yeast express one PI3K (Vps34), three PI4Ks (Lsb6, Pik1, and Stt4), one PtdIns-4-P 5-OH kinase (Mss4), and one PtdIns-3-P 5-OH kinase (Fab1) (Fig. 2) (Flanagan et al., 1993; Schu et al., 1993; Yoshida et al., 1994a; Yoshida et al., 1994b; Yamamoto et al., 1995; Madania et al., 1999; Han et al., 2002; Strahl and Thorner, 2007). Of these enzymes, all but one executes unique biological functions linked to their respective lipid kinase activities. Lsb6 remains functionally enigmatic.

\section{Phosphoinositide phosphatases: classification and catalytic mechanisms}

Phospholipase-independent mechanisms of phosphoinositide degradation are executed by dephosphorylation of phosphoinositides at the D-3, D-4 and/or D-5 positions of the inositol ring (Fig. 1), and the responsible phosphoinositide phosphatases are highly conserved throughout the eukaryotic kingdom. Unlike the case of PtdIns- and phosphoinositide-kinases, some yeast phosphoinositide phosphatases are promiscuous enzymes with regard to substrate specificity -- individual enzymes often dephosphorylate multiple phosphoinositide species (Strahl and Thorner, 2007). The seven known yeast phosphoinositide phosphatases are classified into three different subgroups on the basis of their catalytic domain properties. These include the SAC-domain phosphatases, the inositol polyphosphate 5-phosphatase domain enzymes, and the myotubularin ortholog Ymr1 (Fig. 4;Strahl and Thorner, 2007). Mammalian phosphatases are classified into two superfamilies: the protein tyrosine phosphatase superfamily, and the inositide polyphosphate phosphatase superfamily.

The phosphoinositide phosphatases of the PTP-superfamily fall into four primary classes. The phosphoinositide 4-phosphatases fall into types I and II that share 37\% primary sequence identity, and primarily degrade PtdIns-3,4-P 2 to PtdIns-3-P (Norris et al., 1997; Nystuen et al., 2001). The weeble ataxia mouse is deficient in the type 1 enzyme (Nystuen et al., 2001). PTEN, the famous PtdIns-3,4,5- $\mathrm{P}_{3}$ 3-phosphatase, also belongs to the PTP-superfamily. The Sac1-like phosphoinositide phosphatases fall into two categories - the stand-alone SACdomain enzymes that show relaxed positional specificity with regard to phosphoinositide 
substrate, and the dual functional enzymes that exhibit tandem arrangements of SAC-domains appended to phosphoinositide 5-phosphatase domains (e.g. the synaptojanins). Finally, the myotubularins constitute an intriguing class of phosphoinositide 3-phosphatases.

Phosphoinositide phosphatases of the PTP superfamily are metal-independent enzymes that exhibit a signature Cys- $\mathrm{X}_{5}$-Arg-Thr/Ser $\left(\mathrm{CX}_{5} \mathrm{RT} / \mathrm{S}\right)$ active site motif which physically cradles the various chemical steps of the reaction mechanism (Fig. 4A). First, the $\mathrm{PO}_{3}$ moiety from the phospho-inositol headgroup is accepted by the nucleophilic cysteine residue within the $\mathrm{CX}_{5} \mathrm{RT} / \mathrm{S}$ motif to generate a phosphocysteine intermediate. The invariant arginine of the $\mathrm{CX}_{5} \mathrm{RT} / \mathrm{S}$ motif stabilizes the transition-state so that the $\mathrm{PO}_{3}$ moiety is subsequently transferred to a water molecule. Finally, a conserved aspartic acid from an adjacent structural loop completes the catalytic cycle by protonating the leaving-group oxygen and reconstituting an uncharged hydroxy group at the position from which the phosphate moiety was originally removed (Guan and Dixon, 1991;Fauman and Saper, 1996;Hughes et al., 2000a).

The phosphoinositide 5-phosphatases fall into four categories. The group I enzymes act only

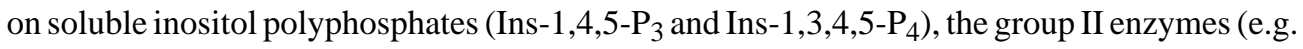
OCRL1; discussed at length below) utilize both phosphoinositide RIPT and soluble inositol phosphate substrates, and the group III enzymes (e.g. SHIP1 and SHIP2; see below) utilize phosphoinositides as preferred substrates. Finally, the group IV enzymes act exclusively on PtdIns-3,4,5- $\mathrm{P}_{3}$ and PtdIns-4,5- $\mathrm{P}_{2}$.

The inositol polyphosphate 5-phosphatase exhibit structural folds similar to those of $\mathrm{Mg}^{2+}$ dependent endonucleases, and all of these enzymes exhibit magnesium-dependent phosphomonoesterase activities (Mitchell et al., 1996; Blero et al., 2007; Majerus and York, 2009). Bioinformatic approaches, coupled with mutagenesis studies, further indicate the inositol polyphosphate 5-phosphatases share the same principle catalytic mechanism as the apurinic/apyrimidinic base excision repair endonucleases (Dlakić, 2000; Whisstock et al., 2000). The model catalytic mechanism employs a nucleophilic water molecule that is positioned and activated by an invariant Asp residue - a residue that is itself properly oriented by H-bonding to the side-chain of a conserved Asn (Fig. 4B). The target 5'-phosphate group of the inositol headgroup is configured for the nucleophilic attack by an invariant His/Asp pair and an invariant Asn. A metal ion $\left(\mathrm{Mg}^{2+}\right)$ stabilizes the transition state of the inversion of configuration of the phosphate with the result that the $\mathrm{PO}_{3}$ moiety is transfered to water and the dephosphorylated inositol phospholipid product is released (Fig. 4B). It is not clear whether the proton donor that stabilizes the inositol leaving group is a water molecule or some other functional group of the enzyme (Whisstock et al., 2000).

Phosphatases of both the double-displacement class (i.e. members of the PTP superfamily that displace the inositol leaving group via an active-site nucleophile and phospho-enzyme intermediate; Fig. 4A), and the class of phosphatases that catalyze direct displacement of the inositol leaving group via nucleophilic water (i.e. members of the inositol polyphosphate 5phosphatase family; Fig. 4B), are truly remarkable enzymes with regard to their catalytic proficiencies (Lad et al., 2003). Both classes of enzymes enhance reaction rates some 17- to 20-orders of magnitude over spontaneous rates. That is, the reactions catalyzed by phosphatases at subsecond time scales occur spontaneously with half-times of ca. $1 \times 10^{12}$ years (Lad et al., 2003)!

This review is focused on the phosphoinositide phosphatases and their various involvements in membrane trafficking and cellular homeostasis. Linkage of individual enzymes to mammalian disease is also discussed. For purposes of clarity, the domain organizations of the relevant phosphoinositide phosphatases are illustrated in Fig. 5, while the subcellular distributions of the various phosphoinositide phosphatases are illustrated in Fig. 6. 


\section{Phosphoinositide 3-Phosphate Phosphatases PTEN}

The PTEN/MMACl/TEPI (phosphatase and tensin homolog/mutated in multiple advanced cancers/ $\underline{\mathbf{T}}$ GF $\beta$-regulated and epithelial cell-enriched phosphatase) gene was originally identified as a candidate tumor suppressor gene located on human chromosome 10q23 ( $\mathrm{Li}$ and Sun, 1997; Li et al., 1997; Myers et al., 1997; Steck et al., 1997; Ali et al., 1999). PTEN harbors the $\mathrm{CX}_{5} \mathrm{RT} / \mathrm{S}$ phosphatase catalytic signature and shares primary sequence similarity with members of the protein tyrosine phosphatase superfamily - a circumstance that prompted the initial suggestion that PTEN is a protein phosphatase. This hypothesis is not supported by biochemical characterizations which indicate recombinant PTEN is a poor protein phosphatase in vitro, irrespective of whether the enzyme is presented with phospho-Ser, phospho-Thr or phospho-Tyr substrates (Li and Sun, 1997; Li et al., 1997; Myers et al., 1997). Rather, PTEN exhibits a significant phosphoinositide phosphatase activity that targets the D-3 phosphate of PtdIns-3-P, PtdIns-3,4- $\mathrm{P}_{2}$ and PtdIns-3,4,5- $\mathrm{P}_{3}$ substrates. PtdIns-3,4,5- $\mathrm{P}_{3}$ is the preferred substrate in vitro and is a primary PTEN substrate in vivo (Myers et al., 1997; Maehama and Dixon, 1998). The unimpressive activity of PTEN towards phosphopeptide substrates, while consistent with the idea it is a primarily lipid phosphatase, does not exclude the possibility that PTEN is also a protein phosphatase -- but one with an exquisite substrate specificity. This issue is further discussed below.

PTEN consists of a ca. 200 residue N-terminal phosphatase domain required for catalytic activity (Fig 6; Lee et al., 1999;Maehama et al., 2001). The PTEN CX $\mathrm{P}_{5} \mathrm{R}(\mathrm{S} / \mathrm{T})$ motif resides within an enlarged active site that surrounds the catalytic signature with three basic residues, and these residues are critical for PTEN lipid phosphatase activity (Maehama et al., 2001). This structural arrangement endows PTEN with its preference for highly acidic phospholipid

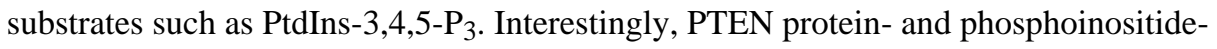
phosphatase activities can be uncoupled. The $\mathrm{G}_{129} \mathrm{E}$ missense mutation alters the phosphoinositide binding pocket and selectively eliminates PTEN phosphoinositidephosphatase activity in vitro (Myers et al., 1998).

That PtdIns-3,4,5- $\mathrm{P}_{3}$ is a PTEN substrate is of great interest as this phosphoinositide is the terminal lipid product of forward PI3K signaling and, as such, represents a potent promoter of cell growth and survival. PtdIns-3,4,5- $\mathrm{P}_{3}$ exerts its proliferative effects by activating the Ser/ Thr protein kinase PDK1. In turn, PDK1 activates the proto-oncogenic protein kinase Akt which contains a PtdIns-3,4,5-P - responsive PH domain (Coffer et al., 1998; Fruman et al., 1998; Rameh and Cantley, 1999; Downes et al., 2007). That PTEN is truly involved in PtdIns-3,4,5- $\mathrm{P}_{3}$-mediated activation of Akt is supported by demonstrations that both cellular PtdIns-3,4,5- $\mathrm{P}_{3}$ and activated Akt levels are constitutively elevated in PTEN-deficient mouse embryonic fibroblasts (Sun et al., 1999; Stambolic et al., 2000). Reciprocally, PTEN overexpression downregulates Akt activity and depresses cellular PtdIns-3,4,5-P $\mathrm{P}_{3}$ levels (Di Cristofano et al., 1998; Cantley and Neel, 1999; Di Cristofano et al., 1999). These data identify PTEN as an antagonist of proliferative signaling - i.e. a tumour suppressor. Consistent with a homeostatic function, PTEN is ubiquitously expressed throughout early embryogenesis in mammals (Di Cristofano et al., 1998; Sun et al., 1999; Suzuki et al., 2008).

It is difficult to overstate the enormous significance of the PtdIns-3,4,5-P 3 /AKT/PTEN regulatory circuit from the standpoint of human disease. Over the past two decades, PTEN has blossomed into one of the featured molecules in cancer biology. Hundreds of published reports focus on PTEN structure, function, and mutations in the context of various human diseases. After p53, PTEN is the most commonly mutated gene in human cancer, and the most deleted/ mutated phosphatase in human sporadic and hereditary cancer syndromes such as Cowden disease, glioblastoma, prostate and endometrial cancers, Bannayan - Zonana syndrome, and 
Lhermitte - Duclos disease, among others (Liaw et al., 1997; Nelen et al., 1997; Stiles, et al., 2004; Suzuki et al., 2008). As some of these syndromes are sensitive to inhibitors of the Target-of Rapamycin (TOR) pathway, and are at least superficially phenocopied by overexpression of downstream components of the TOR pathway, PTEN deficiencies evoke their homeostatic defects in part via deranged TOR signaling (Podsypanina et al., 2001; Atkins et al., 2004; Wendel et al., 2004; Chan et al., 2005). Consistent with a role for PTEN as critical regulator of cellular homeostasis, PTEN nullizygosity in mice results in early embryonic lethality, and heterozygosity results in elevated incidence of various cancers and autoimmune diseases (reviewed in Stiles et al., 2004; Suzuki et al., 2008). PTEN and p53 also show a functional connection. PTEN transcriptional expression is activated by p53, and this circuit contributes to initiation of p53-dependent apoptotic responses and p53-dependent senescence programs as consequences of downregulated PtdIns 3-OH kinase signaling (Jin and Levine, 2001; Stambolic et al., 2001; Feng et al., 2005).

The dual activities of PTEN as a protein tyrosine- and a phosphoinositide-phosphatase pose the interesting question of which activity is the most directly relevant for PTEN action as tumour suppressor. This issue was initially brought to the fore by reports that PTEN protein tyrosine phosphatase activity is directed at key signaling proteins such as focal adhesion kinase and the adaptor protein Shc (Gu et al., 1998; Gu et al., 1999; Yamada and Araki, 2001). However, the available data fall most convincingly in favor of the phosphoinositide phosphatase activity representing the key anti-proliferative activity of PTEN. The PTEN $^{\mathrm{G} 129 \mathrm{E}}$ separation of function allele does not compromise PTEN tumour suppressor activity (Myers et al., 1998), and studies in D. melanogaster demonstrate that PTEN-deficient flies are rescued by mutation of the PtdIns-3,4,5- $\mathrm{P}_{3}$-specific PH domain of Akt (Stocker et al., 2002).

Although PTEN protein tyrosine phosphatase activity does not play a major role in tumour suppressor function, several lines of evidence suggest the PTEN tyrosine protein phosphatase activity is of relevance in specific physiological contexts (Vasquez et al., 2000; Raftopolou et al., 2004; Vogelmann et al., 2005; Leslie et al., 2007; Leslie et al.,2009). Although $\beta$-catenin is proposed as a direct target for PTEN protein tyrosine phosphatase activity (Vogelmann et al., 2005), the best data suggest PTEN catalyzes an auto-dephosphorylation reaction in order to promote the conformational transitions required for the priming of PTEN C-terminal domains for physiologically important protein binding functions (Vasquez et al., 2000; Vasquez et al., 2001; Raftopolou et al., 2004; Leslie et al., 2007; Leslie et al., 2009). A thorough test of these hypotheses will be greatly facilitated by PTEN mutations that selectively inactivate protein tyrosine phosphatase activity without compromising lipid phosphatase activity.

The central role for PTEN is attenuating proliferative signaling demands the enzyme be tightly regulated - both spatially and temporally. The domain structure of the phosphatase suggests this is indeed the case. A lipid-binding $\mathrm{C} 2$ domain is configured C-terminal to the phosphatase domain, and PTEN exhibits a PDZ-binding motif at its C-terminus (Fig 6). The latter motif is proposed to regulate PTEN subcellular localization via interactions with PDZ domaincontaining scaffolding proteins typically associated with the sub-plasma membrane cytoskeleton -- such as the membrane associated guanylate kinase-like protein MAG1 (Lee et al., 1999; Wu et al., 2000; Vazquez et al., 2001). With regard to localization, PTEN exhibits a rather broad distribution across intracellular compartments; having been reported to localize to the plasma membrane, Golgi complex and nucleus (Fig. 6;Myers et al., 1998; Lee et al., 1999;De Matteis and Godi, 2004a). In this regard, while PTEN is evolutionarily conserved throughout the eukaryotic kingdom (with homologs in yeast, Drosophila, C. elegans and mammals), the domain arrangements vary among the various forms. For instance, the $\mathrm{C} 2$ domain is absent from PTEN enzymes of simpler eukaryotes, and the Drosophila and C. elegans PTEN proteins exhibit longer C-terminal tails than does human PTEN. The PDZ- 
binding domain is also missing from some Drosophila PTEN isoforms (Goberdhan et al., 1999; Lee et al., 1999; Maehama et al., 2001;Goberdhan and Wilson, 2003).

In addition to the two lipid-binding signatures recognized by sequence homologies, PTEN also exhibits a conserved $\mathrm{N}$-terminal polybasic motif. This motif is interrupted by $\mathrm{K}_{13} \mathrm{E}$ missense substitution recovered from a sporadic human glioblastoma -- the consequences of which include diminished activation of PTEN phosphatase activity by PtdIns-4,5- $\mathrm{P}_{2}$ and nonfunctionality of the mutant protein in a variety of in vivo contexts (Walker et al., 2004). Because the substitution does not compromise PTEN ${ }^{\mathrm{K} 13 \mathrm{E}}$ activity against soluble Ins-1,3,4,5- $\mathrm{P}_{4}$, i.e. the soluble cognate of the PtdIns-3,4,5- $\mathrm{P}_{3}$ headgroup, or PtdIns-3,4,5- $\mathrm{P}_{3}$ incorporated into neutral phosphatidylcholine liposomes, the data suggest this polybasic motif binds nonsubstrate acidic phospholipids to orient PTEN onto membrane surfaces for optimal activity against its lipid substrates. In support of this conclusion, myristoylation of the PTEN ${ }^{\mathrm{K} 13 \mathrm{E}} \mathrm{N}$ terminus restores protein function (Walker et al., 2004). Further evidence for the functional importance of the PTEN N-terminus is provided by the $\mathrm{S}_{10} \mathrm{~N}$ missense substitution identified from a non-Hodgkins malignant lymphoma (Bonneau and Longy, 2000). PTENS ${ }_{10} \mathrm{~N}$ exhibits respectable catalytic activity in vitro, suggesting the mutant enzyme is defective in some regulatory aspect (Han et al., 2000). In that regard, the $S_{10} \mathrm{~N}$ substitution lies within the basic cluster interrupted by the $\mathrm{K}_{13} \mathrm{E}$ substitution.

PTEN activity is also regulated by interesting sets of binding partners. Recently, it was reported that transport of PTEN to the neuronal plasma membrane, presumably the primary site at which it encounters its PtdIns-3,4,5-P3 substrate, is controlled by the actin-based motor protein myosin Va (van Diepen et al., 2009). A combination of co-immunoprecipitation and Förster resonance energy transfer experiments suggest a direct interaction between PTEN and myosin $\mathrm{Va}$, and indicate the interaction is promoted by phosphorylation of PTEN by casein kinase 2 and glycogen synthase kinase 3. Myosin Va deficiencies, as well as PTEN defects, lead to increased size of neuronal cells in a manner that is dependent on PtdIns 3-OK kinase and mTOR signaling (Mercer et al., 1991; van Diepen et al., 2009). Following a similar theme, the Drosophila PTEN associates directly with the Par-3 component of the PAR/atypical protein kinase C complex involved in establishment and maintenance of cell polarity (von Stein et al., 2005). In fly ovaries and embryos lacking PTEN, the actin cytoskeleton is disorganized. Failures in asymmetric distribution of specific mRNAs, in posterior movements and synchronous nuclear divisions, and in cellularization, are also observed (von Stein et al., 2005).

Finally, regulation of PTEN activity by a binding partner has been documented. Peroxiredoxin 1 (Prdx1), a low efficiency peroxidase scavenges reactive oxygen species binds PTEN through its C2 domain (Cao et al., 2009). The Prdx 1-PTEN interaction prevents inactivation of PTEN by reactive oxygen species. This finding, when coupled with the rather unimpressive catalytic efficiency of Prdx1, suggests a privileged relationship between PTEN and Prdx1. Reductions in Prdx1 activity result in enhanced basal and peroxide- and growth factor-induced Akt signaling (Cao et al., 2009).

\section{PTEN2, TPTE and TPIP}

Humans express several other proteins with primary sequence similarity to PTEN. These include PTEN2, the Transmembrane Phosphatase with TEnsin homology (TPTE), and the

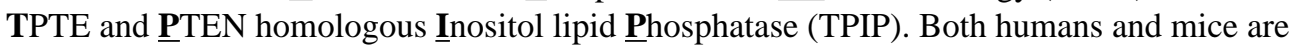
reported to express PTEN2 proteins (Wu et al., 2001). Murine PTEN2 is a testes-specific protein expressed primarily in secondary spermatocytes and early spermatids - an expression pattern suggestive of a role for this protein in the terminal stages of spermatocyte differentiation. The protein localizes to the medial/trans-compartments of the Golgi complex, and is reported to have detectable phosphoinositide 3-phosphatase activity with a substrate 
specificity resembling that described for PTEN (Wu et al., 2001). A signature feature of PTEN2 that distinguishes it from PTEN is presence of an extended N-terminal domain that contains four putative transmembrane domains. This extension is necessary and sufficient for localization of murine PTEN2 to Golgi membranes, and these transmembrane domains have been speculated (with no real evidence in support) as having the potential to form an ion channel (Wu et al., 2001).

Human TPTE and TPIP proteins were independently identified by several groups, and these species also harbor 2 or 3 putative transmembrane domains in their N-termini (Chen et al., 1999; Walker et al., 2001). The mouse contains only a single TPTE gene from which various spliceoforms are generated, while humans express perhaps as many as three functional TPTE structural genes (Guipponi et al., 2001). Nothing is known whether these TPTE gene products are functionally distinct in any significant way. With regard to human TPTE, of which two isoforms (TPTE $\alpha$ and TPTE $\beta$ ) have been characterized in some detail, Walker et al. (2001) find these proteins to be devoid of phosphoinositide phosphatase activities and to localize to the plasma membrane. The inactivity of these proteins as phosphoinositide phosphatases is consistent with the presence of missense substitutions that introduce acidic residues in the active site pocket, substitutions whose PTEN cognates compromise the phosphoinositide-3phosphatase activities of this enzyme (Walker et al., 2001). Some confusion has arisen after the assignment of murine PTEN2 by Wu et al. (2001) as the orthologue of the human TPTE $\alpha$ described by Chen et al. (1999). The enzymatic and localization properties of human TPTE $\alpha$ reported by Walker et al. (2001) diverge significantly from those reported for murine PTEN2 by Wu et al. (2001). It is argued on the basis of these differences that murine PTEN2 and human TPTE $\alpha$ proteins are not orthologous (Walker et al., 2001).

TPIPs are characterized as novel PTEN homologs that are expressed as two predominant isoforms designated TPIP $\alpha$ and TPIP $\beta$ (Chen et al., 1999; Walker et al., 2001). TPIP $\alpha$ is homologous to PTEN within the phosphatase and C2 domains (Fig. 6), but lacks the C-terminal tail which harbors the PDZ-binding domain and phosphorylation sites proposed to regulate PTEN stability and activity (Maehama et al., 2001; Simpson and Parsons, 2001; Walker $e t$ al., 2001). This isoform exhibits clearly measurable phosphoinositide 3-phosphatase activity (but little of any Ins-1,3,4,5- $\mathrm{P}_{4}$ ) phosphatase activity), is expressed most highly in testis, brain and stomach, exhibits two or three potential trans-membrane domains in its $\mathrm{N}$-terminal region, and localizes to the ER (Walker et al., 2001). By contrast, TPIP $\beta$ is expressed in a testis-specfic manner and is truncated at both the $\mathrm{N}$ - and C-termini relative to TPIP $\alpha$. Thus, TPIP $\beta$ lacks both the putative trans-membrane domain region and the $\mathrm{C} 2$-domain and, consequently, does not bind stably to membranes. Moreover, recombinant TPIP $\beta$ presents no measurable phosphoinositide phosphatase activity (Walker et al., 2001). The collective data indicate the minimal phosphatase requires both the catalytic- and $\mathrm{C} 2$-domains to generate a functional module. Although, TPIP $\alpha$ is a phosphoinositide 3-phosphatase, it does not appear to couple physiologically to the PTEN-sensitive PtdIns-3,4,5- $\mathrm{P}_{3}$ pools involved in activation of PDK1 and Akt (Walker et al., 2001).

\section{The Myotubularins}

Myotubularin (MTM1), the founding member of the myotubularin family, was discovered by isolation of a gene mutated in X-linked centromyotubular myopathy (Laporte et al., 1996). MTM1 is a $\mathrm{CX}_{5} \mathrm{RT} / \mathrm{S}$ motif protein that exhibits potent PtdIns-3-P phosphatase activity (Blondeau et al., 2000; Taylor et al., 2000). The large MTM-related (MTMR) protein family is highly conserved from yeast to man. Humans express 14 MTMR family members and, consistent with how these proteins were discovered, interest in MTMR proteins is stoked by their disease relevance. Mutations in several genes of this family are root causes of myotubular 
myopathy and Charcot-Marie-Tooth peripheral neuropathies (Clague and Lorenzo, 2005; Robinson and Dixon, 2006).

The myotubularins are recognized as key components of the homeostatic strategy for regulation of PtdIns 3-phosphate and PtdIns-3,5- $\mathrm{P}_{2}$ levels in eukaryotic cells (Maehama et al., 2001; Tronchere et al., 2003; Tronchere et al., 2004). Human MTM1, and MTMR1,2,3,4,6,7 are phosphoinositide 3-phosphate phosphatases with substrate preferences restricted to PtdIns-3$\mathrm{P}$ and PtdIns-3,5- $\mathrm{P}_{2}$ (Tronchere et al., 2003; Tronchere et al., 2004). Curiously, nearly half of the metazoan MTM family members contain naturally-occurring missense substitutions that involve the Cys and $\mathrm{Arg}$ residues of the canonical $\mathrm{CX}_{5} \mathrm{R}(\mathrm{S} / \mathrm{T})$ motif, thereby disqualifying these enigmatic proteins as catalytically-active phosphatases (Wishart et al., 2001; Laporte et al., 2003; Taylor and Dixon, 2003; Clague and Lorenzo, 2005; Robinson and Dixon, 2006). In at least several cases, the naturally inactive MTMs -- by virtue of their heterodimerization with catalytically competent members of the MTM family -- play important roles in regulation of mammalian phosphoinositide homeostasis (Clague and Lorenzo, 2005; Robinson and Dixon, 2006). Perhaps the inactive subunits are critical for appropriate presentation of the substrate phosphoinositide to the catalytically active subunit in cellular contexts. This interesting arrangement does not hold for all myotubularins, however. S. cerevisiae expresses a single active MTM1 homolog (yeast myotubularin-related 1; Ymr1), and the yeast genome does not display catalytically-inactive members of this family (Taylor et al., 2000; De Matteis and Godi, 2004a; Robinson and Dixon, 2006).

Metazoan MTMRs are categorized into six subclasses, three of which define groups of naturally inactive phosphatases (Wishart et al., 2001; Laporte et al., 2003; Taylor and Dixon, 2003). The common MTM domain structures include a PHGRAM (pleckstrin homology

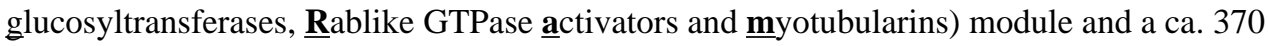
residue central PTP domain (Fig. 5; Begley et al., 2003). Coiled-coil regions that presumably organize interactions with other proteins reside $\mathrm{C}$-terminal to the phosphatase domain in most MTMR proteins. The MTMR3/4 and MTMR5/13 subclasses contain additional conserved modules, including FYVE, DENN and PH domains (Begley et al., 2003; Robinson and Dixon, 2006). Localization studies identify MTMs as peripheral membrane proteins of endosomal compartments (Zhao et al., 2001; Laporte et al., 2002; Mochizuki and Majerus, 2003) - i.e. profiles consistent with involvements of these proteins in control of the PtdIns-3-P and PtdIns-3,5- $\mathrm{P}_{2}$ signaling that is intimately linked to protein trafficking through the endosomal system (Fig 6). PtdIns-3-P and PtdIns-3,5- $\mathrm{P}_{2}$ are present on endosomal compartments -PtdIns-3-P predominates on early endosomes, and PtdIns-3,5- $\mathrm{P}_{2}$ on late endocytic organelle membranes. Insufficiencies in PtdIns-3-P and PtdIns-3,5- $\mathrm{P}_{2}$ phosphatase activity compromise turnover of these endosomal phosphoinositides, derange membrane trafficking through this system, and it is this set of basic cellular malfunctions that manifests itself most strikingly in pathologies of post-mitotic cells (e.g. neurons).

\section{SAC-Domain Phosphoinositide Phosphatases}

The Sac1-like phosphoinositide phosphatases are characterized by a domain arrangement for which the yeast Sac1 protein serves as prototype (Cleves et al., 1989; Chung et al., 1997; Guo et al., 1999). SAC-domain proteins are divided into two subgroups. One group is characterized by a stand-alone Sac domain. Examples include yeast Sac1 and Fig4, and other proteins expressed by various species - e.g. the human KIAA0274, KIAA0851 and KIAA0966 proteins. The second group presents a Sac1-like-phosphatase module configured adjacent to a 5phosphatase domain. Examples include mammalian synaptojanins 1 and 2, and the cognate yeast phosphatases Inp51/Sj11, Inp52/Sj12, and Inp53/Sj13 (Srinivasan et al., 1997; Stolz et al., 1998; Hughes et al., 2000a). 


\section{Yeast and Mammalian Sac1 Phosphatases}

The founding member of the SAC-domain phosphoinositide phosphatase family was identified in yeast by two independent genetic screens searching for novel actin-regulatory proteins and novel regulators of membrane trafficking through the yeast trans-Golgi/endosomal networks, respectively (Cleves et al., 1989; Novick et al., 1989; Whitters et al., 1993). While it was explicitly postulated that Sac1 (suppressor of actin) is an antagonist of 4-phosphoinositide signaling, and that it is this function that accounts for the effects of sacl mutations on actin organization and membrane trafficking (Cleves et al., 1991), the demonstration that Sac1 is a phosphoinositide phosphatase came only eight years later (Guo et al., 1999). Sac1 is a type II integral membrane protein that disposes the $\mathrm{N}$-terminal and $\mathrm{C}$-terminal Sac1 domains to the cytosol (Fig. 5), it localizes to endoplasmic reticulum (ER) and Golgi membranes in yeast and in animal cells (Fig. 6), and the protein is anchored to membranes by two C-terminal transmembrane domains (Cleves et al., 1989; Whitters et al., 1993; Nemoto et al., 2000; Liu et al., 2008; Mayinger, 2009). Sac1 and its orthologs are the only integral membrane proteins of the SAC1-domain family of phosphatases, and this property is essential for optimal catalytic activity in cells (Rivas et al., 1999; Foti et al., 2001). Genetic ablation of Sac1 function in yeast is not a lethal event, and a chromosomal sacl $\triangle 4$ allele recapitulates the genetic interactions exhibited by sacl alleles recovered from the actin- and TGN-directed genetic screens (Cleves et al., 1989). Thus, the two genetic screens through which Sac1 was identified uncovered genuine loss-of-function mutations. Other phenotypes include cold-sensitivity for growth, cell wall abnormalities, and assorted ER-associated defects (Cleves et al., 1989; Novick et al., 1989; Kochendörfer et al., 1999).

Biochemical and in vivo inositol-labeling experiments demonstrate yeast Sac1 and its mammalian homologs are promiscuous phosphoinositide phosphatases that show little positional specificity with regard to phosphoinositide substrate -- PtdIns-3-P, PtdIns-4-P, PtdIns-5-P, and PtdIns-3,5- $\mathrm{P}_{2}$ are all acceptable substrates (Guo et al., 1999). The exceptions to the rule are PtdIns-3,4-P $\mathrm{P}_{2}$ and PtdIns-4,5-P . Thus, Sac1 domains cannot degrade polyphosphoinositides with vicinal phosphates. In yeast, it is clear the major in vivo substrate for Sac1 is PtdIns-4-P; a conclusion rigorously established by headgroup chemical analysis of the predominant phosphoinositide species that accumulates in Sac1-deficient yeast (Guo et al., 1999; Rivas et al., 1999). Indeed, genetic ablation of Sac1 activity effects 8- to 10-fold increases in PtdIns-4-P mass in yeast with little effect on the other phosphoinositides (Guo et al., 1999; Rivas et al., 1999; Hughes et al., 2000a; Hughes et al., 2000b; Nemoto et al., 2000). The massive accumulation of PtdIns-4-P is a large part of the mechanism, but not the entire mechanism, for why Sac1 defects alter membrane trafficking from the yeast TGN (Xie et al., 1998; Rivas et al., 1999; Li et al., 2002). Thus, the in vitro promiscuity of the enzyme notwithstanding, Sac1 exhibits impressive substrate specificity in vivo. This substrate specificity is likely a revealing manifestation of how the enzyme encounters its substrate phosphoinositides.

The Sac1 substrate specificity is all the more intriguing in that not all PtdIns-4-P pools are accessed by Sac1. The source of PtdIns-4-P matters as, at least under normal growth conditions, yeast Sac1 specifically degrades the PtdIns-4-P generated by one of the two essential PtdIns 4-OH kinases in yeast - i.e. the plasma membrane isoform Stt4 - with insignificant access to the PtdIns-4-P pool generated by the other essential yeast PtdIns 4-OH kinase Pik1 (Nemoto et al., 2000; Foti et al., 2001; Routt et al., 2005). This intriguing functional relationship is not well understood given the localization of Stt4 to the plasma membrane and Sac1 residence in intracellular membrane compartments. Ideas for how to reconcile this apparent physical paradox are emerging (see below). The effects of Sac1 dysfunction are not limited to PtdIns-4P. Larger derangements of lipid metabolism are apparent in Sac1-deficient yeast - particularly in neutral lipid metabolism (Kearns et al., 1997; Rivas et al., 1999; Foti et al., 2001). 
Sac1 cycles between the ER and Golgi - indicating cells impose regulatory oversight on the mechanisms by which Sac1 is retained in, and retrieved from, distinct intracellular compartments. As discussed below, interesting cell biology is associated with such a trafficking itinerary. Retention of Sac1 in the yeast ER is reported to be mediated by an interaction of the Sac1 C-terminal tail with Dpm1, the highly abundant ER dolicholphosphate-mannose synthase. Functional ablation of this interaction disrupts ER localization of the enzyme (Faulhammer et al., 2005). How yeast Sac1 is recognized as a retrograde cargo in Golgi membranes is not understood.

A different strategy for Sac1 traffic control is in evidence in mammalian cells. Whereas Sac1 also cycles between the mammalian ER and Golgi, its competence for exit from the ER compartment requires oligomerization of the enzyme via a leucine-zipper motif - a motif not present in yeast Sac1 (Blagoveshchenskaya et al., 2008). How the enzyme is retrieved from Golgi compartments back to the ER is known, however. Mammalian Sac1 presents a Cterminal KXKXX motif that serves as binding site for the coatomer (COPI) complex, the presumptive coat for retrograde trafficking vesicles, and is obligately required for retrieval of the enzyme from the Golgi back to the ER (Fig. 5; Rohde et al., 2003; Liu et al., 2008). Interaction of Sac1 with the COP1 machinery requires disassembly of the Sac1 oligomers. Functional integrity of the Sac1/COPI complex also demands that Sac1 be an active phosphatase, and assembly of this complex is dynamically regulated by cell-growth conditions (Rohde et al., 2003; Blagoveshchenskaya et al., 2008; Liu et al., 2008). How Sac1 phosphatase activity regulates this interaction is unclear, but some phosphoinositide species (PtdIns-4-P?) likely inhibit the interaction - directly or indirectly. Such a mechanism promises a different paradigm for how phosphoinositides regulate cargo::vesicle coat protein interactions. In the late secretory and endocytic pathways, phosphoinositides are positive regulators that faciltitate cargo interactions with coat proteins (De Matteis and Godi, 2004a; Mayinger, 2009). At any rate, it is abundantly clear that endogenous Sac1 levels (at least in yeast) are saturating -- given that 20-fold overproduction of Sac1 protein has no effect on cell viability, phosphoinositide homeostasis, or ER localization of the enzyme (Cleves et al., 1989; Rivas et al., 1999; Liu et al., 2008).

Unlike the case in yeast, the single mammalian Sac1 isoform executes essential cellular functions (Liu et al., 2008). Nullizygous embryos exhibit pre-implantation lethality obvious by the blastocyst stage, and siRNA experiments report a loss of viability upon acute Sac1 depletion in cultured mammalian cells. One obvious intracellular phenotype associated with Sac1-depletion is a manifest disorganization of cis-, medial-and trans-Golgi compartments in the absence of obvious morphological derangements of other compartments of the secretory pathway. The structurally disturbed Golgi membranes show no overt membrane trafficking defects, however (Liu et al., 2008). Instead, Sac1-depleted cells fail to exit mitosis and present a high incidence of spindle disorganization highlighted by ectopic and mechanically-active spindle asters. These deviant spindle asters are marked with $\gamma$-tubulin but, as is normally the case, only two of the asters harbor centrosomal Centrin-2 landmarks. Thus, licensing of centrosome division is unperturbed in Sac1-deficient cells. The mechanical activity of ectopic spindle asters, when coupled with the failure of multipolar spindles to efficiently resolve, promotes catastrophic defects in chromosomal segregation (Liu et al., 2008). Complementation experiments show Sac1 phosphoinositide phosphatase activity, and recycling from the Golgi back to the ER, are functional properties required for Sac1 activity in vivo (Liu et al., 2008).

Why is Sac1 ER-localization a conserved and functionally important feature for this phosphoinositide phosphatase? The ER is not a compartment generally associated with phosphoinositide signaling. One possibility is Sac1 scavenges 'wandering' phosphoinositides in the ER for the purpose of degrading mislocalized phosphoinositide molecules that would otherwise confuse phosphoinositide-centric mechanisms for establishing and maintaining 
organelle identity. This model confronts two issues. First, Sac1 is particularly tuned to activity of the plasma membrane Stt4 (mammalian PtdIns kinase $\alpha$ ), yet inactivation of this circuit is not lethal in yeast nor is the secretory pathway particularly confused regarding organelle identities in sacl $\Delta$ cells that accumulate dramatic amounts of PtdIns-4-P. While Sac1-deficient mammalian cells do not thrive, these nonetheless traffic proteins quite normally - even though Golgi structure is deranged (Liu et al., 2008). On balance, it does not seem likely that Sac1 plays dedicated phosphoinositide cleanup duty with the ER as repository for mislocalized phosphoinositides. It would seem surface dilution of phosphoinositide across a large ER area would confound such cleanup strategies anyway.

Alternatively, Sac1 may coordinate plasma membrane and ER functions and, by orienting itself on the ER surface at points of apposition with the plasma membrane (membrane contact sites?), degrade excess phosphoinositide on the plasma membrane. If that were the simple case, one would expect significant and specific PtdIns-4-P accumulation in the plasma membrane in Sac1-deficient cells. Although there is one report to suggest this is the case (Roy and Levine, 2004), other experiments report PtdIns-4-P accumulation in ER-like compartments of Sac1deficient yeast cells (Li et al., 2002; Woods et al., 2009). These phosphoinositide localization data yeast amply demonstrate the reporter-dependence of the visualized phosphoinositide profile, emphasizing yet again that caution must be exercised in interpreting the results obtained with such biosensors. The idea that Sac1 is either a component of, or takes advantage of, membrane contact sites to access specific PtdIns-4-P pools remains an open question. More expansive discussions of putative membrane contact sites are found in several recent treatments of this topic (Pichler et al., 2001; Levine and Loewen, 2006; Peretti et al., 2008).

The involvement of mammalian Sac1 in cell cycle progression and mitotic spindle organization, suggests the simplest possibility may hold the most merit. That is, Sac1 localizes to the ER because it regulates phosphoinositide-mediated signal transduction from cytosolic compartments, perhaps even the ER, to the nucleus or nuclear envelope. The nuclear matrix is an active compartment for phosphoinositide-signaling (Cocco et al., 1987; Divecha et al., 1991; Irvine and Divecha, 1992; Irvine, 2003; Martelli et al., 2005; Gonzales and Anderson, 2006), and one can imagine a dedicated role for an ER-localized phosphatase in survey of phosphoinositide status on the nuclear envelope (which is contiguous with the ER). Nuclear pores are attractive sites for such surveillance. It is around these structures that continuities occur between the cytosolic membrane leaflet of the ER/nuclear envelope and the leaflet that faces the nuclear matrix.

Alternatively, Sac1 may regulate nuclear envelope dynamics in specific physiological contexts. Nuclear envelope assembly and disassembly occurs during the mammalian mitotic cycle, and the process is also highly regulated in non-somatic cells such as fertilized oocytes (Larijani and Poccia, 2009). Evidence for a direct role for phosphoinositides in regulating nuclear envelope assembly is provided by Larijani and colleagues who demonstrated sea urchin nuclear envelope precursor vesicles (i.e. vesicles that must fuse for completion of envelope assembly) exhibit a highly unusual lipid composition -- one strikingly enriched in sterols and phosphoinositides (Byrne et al., 2007; Garnier-Lhomme et al., 2009).

Other possibilities for why Sac1 localizes to the ER include compartment-specific involvements for Sac 1 in integration of nutrient/growth factor status with activity of membrane trafficking through the late stages of the Golgi complex. Evidence to support such integrator roles for Sac1 has been obtained from both the yeast and mammalian systems, and the principle is based on differential control of the ER-Golgi-ER cycling itinerary of the Sac1 phosphatase (Fig. 7). When yeast are cultured in nutrient-replete conditions, Sac1 is retained in the ER where it stimulates Dpm activity in ER oligosaccharide biosynthesis (Faulhammer et al., 2005). Efficient glycosylation of proteins is a critical component of ER quality control 
mechanisms that survey cargo incorporation into the secretory pathway (Hebert et al., 2005; Meusser et al., 2005). Upon glucose starvation, Sac1 redistributes from the yeast ER to the Golgi system where it is suggested to depress Golgi secretory activity by depleting Golgi membrane PtdIns-4-P pools. In this manner, Sac1 is proposed to function as a pro-secretory molecule when growth conditions are favorable, and as a brake when conditions are poor (Fig. 7;Faulhammer et al., 2005;Blagoveshchenskaya et al., 2008;Mayinger, 2009).

Analogous Sac1-mediated mechanisms for coupling membrane trafficking to growth factor status also operate in mammalian cells. In this case, homo-oligomerization of Sac1 via its leucine zipper motif must occur in a regulated manner to support timely COPII-mediated exit of the phosphatase from the ER, and the complexes must be disassembled on demand in the Golgi complex to promote timely COP1-mediated retrieval of the phosphatase back to the ER (Fig. 7; Blagoveshchenskaya et al., 2008;Mayinger, 2009). The p38 mitogen-activated protein kinase and extracellular signal-regulated kinases $1 / 2$ regulate these events (Blagoveshchenskaya et al., 2008).

How physiologically significant is the complex Sac1 trafficking itinerary in yeast and mammals? As the bulk of the experiments that describe the linkage between Sac1 trafficking and nutrient/mitogen signaling report correlative relationships, this remains an open question. In support of views that assign high physiological significance to Sac1 traffic control are demonstrations that yeast Sac1 expression cannot rescue Sac1 deficiencies mammalian cells (Liu et al., 2008) -- presumably because yeast Sac1 is not outfitted to heed the various mitogenic signals that normally control the dynamic cycling of mammalian Sac1 between ER and Golgi. In opposition, tethering of the Sac1 catalytic domain to an ER-localized integral membrane protein Sec61 generates an ER-localized chimera whose expression is sufficient to fully complement all known phenotypes associated with Sac1 loss-of-function in yeast ( $\mathrm{Li}$ et al., 2002). Presumably, this chimera is uncoupled from the principle regulatory mechanisms that couple yeast nutrient sensing to Sac1 trafficking. Moreover, expression of mammalian Sac1 in yeast, a protein also expected to be indifferent to the mechanisms controlling the yeast Sac1 trafficking itinerary, demonstrates it to be an effective surrogate for endogenous Sac1 (Liu et al., 2008). One possibility for reconciling these various data is that yeast might be less sensitive to subversion of dynamic Sac1 trafficking than are mammalian cells. Another possibility is that normal laboratory conditions are inappropriate contexts in which to examine this question. Nevertheless, the concept of Sac1 as integrator of nutrient/mitogen-sensing with membrane trafficking is an enticing one that will enjoy its share of future experimental scrutiny. While, to our knowledge, there is as yet no direct linkage between Sac1 dysfunction and disease, establishment of such a linkage will drive further interest in this under-investigated phosphoinositide phosphatase. In that regard, work in Drosophila demonstrates that Sac1 hypomorphism results in embryonic lethality associated with defects in dorsal closure of the mutant embryo and deranged activation of the Jun N-terminal kinase MAPK signaling cascade (Wei et al., 2003).

\section{Yeast and Mammalian Fig4 Phosphatases}

Another important member of the SAC-domain phosphatase family is Fig4 (Factor induced gene; Fig. 5). First identified in yeast through a large-scale enhancer trap screen designed to identify genes whose expression is regulated by mating pheromone (Erdman et al., 1998), Fig4 does not discharge essential functions in yeast. It is, however, required for normal mating projection formation and actin polarization in response to mating pheromone (Erdman et al., 1998). Fig4 harbors intrinsic polyphosphoinositide phosphatase activity with positional specificity for the D-5 phosphoester bond of PtdIns-3,5- $\mathrm{P}_{2}$, is localized to the vacuolar membrane, and insufficiencies cause defects in vacuole fission with the result that vacuoles become enlarged and retrograde trafficking through the endosomal system is also impaired 
(Bonangelino et al., 2002; Gary et al., 2002;Michell et al., 2006;Michell and Dove, 2009). Paradoxically, Fig4 is required for activation of the Fab1 PtdIns-3-P 5-OH kinase that produces the PtdIns-3,5-P $\mathrm{P}_{2}$ which, in turn, is degraded by Fig4 (Gary et al., 2002;Rudge et al., 2004;Duex et al., 2006a;Duex et al., 2006b). It is for this reason that Fig4 loss-of-function mutations evoke reduced, rather than elevated, intracellular PtdIns-3,5- $\mathrm{P}_{2}$. The physiological rationale for such a paradoxical coupling between a phosphatase and a kinase remains obscure.

The Sac3 PtdIns-3,5- $\mathrm{P}_{2}$ 5-phosphatase is the mammalian ortholog of yeast Fig4 (Fig. 5), and defects in this enzyme are associated with Charcot-Marie-Tooth peripheral neuropathies (CMT) that affect motor and sensory nerves and cause progressive distal muscle weakness and atrophy (Quattrone et al., 1996;Berger et al., 2006;Nicot and Laporte, 2008). Haploinsufficiencies for the human $S A C 3$ gene are also associated with autosomal recessive CMT4J neuropathies (Chow et al., 2007). Insertional inactivation of murine SAC3 results in the "pale tremor mouse" syndrome characterized by degeneration of the central nervous system, peripheral neurophathy, and diluted pigmentation. Fibroblasts derived from pale tremor mice exhibit enlarged late endosomal and lysosomal compartments, and reduced levels of PtdIns-3,5- $\mathrm{P}_{2}$ (Chow et al., 2007). Thus, the paradoxical functional relationship between a Fig4 phosphoinositide phosphatase and a Fab1 phosphoinositide kinase is preserved in the cognate mammalian enzymes.

\section{Phosphoinositide 5-Phosphate Phosphatases}

Enzymes of the phosphoinositide 5-phosphatase family dephosphorylate the D-5 phosphoester linkage of PtdIns-3,5- $\mathrm{P}_{2}$, PtdIns-4,5- $\mathrm{P}_{2}$ and PtdIns-3,4,5- $\mathrm{P}_{3}-$ - generating PtdIns-3-P, PtdIns-4$\mathrm{P}$, and PtdIns-3,4- $\mathrm{P}_{2}$, respectively. This enzyme family consists of ten mammalian and four yeast members whose activities intersect with a variety of cellular events such as synaptic vesicle recycling, hematopoietic cell proliferation, insulin signaling, and actin organization (Astle et al., 2006; Ooms et al., 2009). A typical feature of this enzyme family is a ca. 300 residue central catalytic polyphosphate 5-phosphatase domain highlighted by two signature motifs -- WXGDXN(F/Y)R and P(A/S)W(C/T)DRIL -- spaced some 60-75 residues apart (Majerus et al., 1999). Crystallographic studies reveal these 5-phosphatases belong to the AP endonuclease family highlighted by a catalytic mechanism which employs a His/Asp active site pair (Dyson et al., 2005).

\section{Oculocerebrorenal Lowe Syndrome (OCRL) Phosphatase}

OCRL is a devastating human X-linked developmental disorder that occurs in approximately 1 in 200,000 births, and is characterized by a variety of ocular, neurological, cognitive, renal, and musculoskeletal abnormalities (Lowe et al., 1952; Leahey et al., 1993; Hoopes et al., 2005). Ocular syndromes include bilateral congenital cataracts, glaucoma, and microphthalmos. Neonatal hypotonia, mental retardation, araflexia, and behavioral abnormalities represent neurological manifestations. Renal defects include kidney absorbtion insufficiencies associated with Fanconi syndrome of kidney proximal tubules and type 2 Dent disease. The kidney malabsorbtion phenotypes contribute to the musculoskeletal defects that are manifested in joint hypermobility and in fracture-prone bones.

The molecular etiology of Lowe's syndrome is loss-of-function for the OCRL1 inositol polyphosphate 5-phosphatase (Attree et al., 1992; Leahey et al., 1993). OCRL1 exhibits three conserved domains -- the central inositol polyphosphate 5-phosphatase domain, an ASH domain, and a C-terminal catalytically inactive Rho guanosine triphosphatase-activating protein (GAP)-like domain (Fig. 5; Lowe, 2005; Erdmann et al., 2007). OCRL1 shares 51\% primary sequence identity with INPP5B, the only other inositol polyphosphate 5-phosphatase with a GAP-like domain in humans and mice (Jefferson and Majerus, 1995; Speed et al., 1995; Matzaris et al., 1998). Both OCRL1 and INPP5B hydrolyze PdIns-4,5- $\mathrm{P}_{2}$ and 
PtdIns-3,4,5- $\mathrm{P}_{3}$, as well as the soluble inositol polyphosphates Ins-1,4,5- $\mathrm{P}_{3}$ and Ins-1,3,4,5$\mathrm{P}_{4}$, but with distinct substrate preferences. While PdIns-4,5- $\mathrm{P}_{2}$ is preferred to PtdIns-3,4,5$\mathrm{P}_{3}$ by both OCRL1 and INPP5B, the latter does not discriminate between molecular species of these phosphoinositides and does not dephosphorylate PtdIns-3,5- $\mathrm{P}_{2}$ (Zhang et al., 1995; Zhang et al., 1998; Schmid et al., 2004). Available evidence suggests INPP5B systematically dephosphorylates PtdIns-3,4,5-P $\mathrm{P}_{3}$ to PtdIns-3-P, a key phosphoinositide required for endosome homeostasis (Shin et al., 2005). Some measure of functional redundancy likely exists between OCRL1 and INPP5B in mice. Combinatorial ablation of OCRL1 and INPP5B structural genes results in embryonic lethality, while OCRL1 nullizygosity does not result in murine Lowe syndrome disease (Janne et al., 1998). Lower eukaryotes (flies, worms and amoeba) express only one of those two proteins, and no GAP-like domain-containing 5-phosphatases are expressed in yeast (Lowe, 2005).

The OCRL1 protein localizes to the trans-Golgi network (TGN) and early endosomes (Fig. 6; Olivos-Glander et al., 1995;Ungewickell et al., 2004; Choudhury et al., 2005;Faucherre et al., 2005). OCRL1 also interacts with the small GTPase Rac and the TGN/endosomal adaptor protein APPL1 via its Rho-GAP domain. These interactions target the enzyme to the TGN/ endosomal system (Faucherre et al., 2003;Erdmann et al., 2007;McCrea et al., 2008). The presence of OCRL1 in clathrin-decorated budding profiles at the TGN, and as cargo in clathrincoated vesicles (CCV) shuttling between the TGN and endosomes, suggests this phosphatase plays a role in vesicular transport between these compartments (Ungewickell et al., 2004; Choudhury et al., 2005). The redistribution of cargo that cycles between TGN and endosomes (e.g. TGN46) to early endosomal compartments (accompanied by endosome enlargement) upon siRNA-mediated OCRL1 depletion supports this view. Thus, retrograde trafficking from endosomes to the TGN is compromised by OCRL1-insufficiencies, and the 5-phosphatase domain is essential for OCRL1-mediated control of this trafficking step (Choudhury et al., 2005). Morever, mutations that reside in non-catalytic domains of OCRL1 (i.e. the RhoGAP-like and ASH domains) all result in mislocalization of the enzyme by compromising its ability to bind APPL1 (Erdmann et al., 2007; McCrea et al., 2008).

The mechanism for how OCRL1 controls clathrin-mediated membrane trafficking through the TGN/endosome system involves regulation of PtdIns-4-P and/or PtdIns-4,5- $\mathrm{P}_{2}$ levels. PtdIns-4-P, together with ARF GTPases, facilitates membrane recruitment of effector proteins (e.g. clathrin adaptors AP1, an AP1/clathrin interacting protein epsinR, and lipid-binding proteins such as oxysterol-binding proteins) that regulate the biogenesis and dynamics of the TGN/endosomal system (Kalthoff et al., 2002; Li et al, 2002; Mills et al., 2003; Wang et al., 2003; Godi et al., 2004). Loss of OCRL1-mediated degradation of PtdIns-4,5-P $\mathrm{P}_{2}$ to PtdIns-4$\mathrm{P}$ in TGN/endosomes might upset balanced recruitment of these effector proteins to membranes due to PtdIns-4-P insufficiency. Alternatively, given PtdIns-4,5- $\mathrm{P}_{2}$ plays an essential role in clathrin-mediated endocytosis, by facilitating recruitment of clathrin accessory proteins to the plasma membrane, OCRL1 inactivation may provoke PtdIns-4,5- $\mathrm{P}_{2}$ derangements which influence the TGN/endosomal system indirectly (Wang et al., 2003; Legendre-Guillemin et al., 2004).

OCRL1 is suggested to regulate actin dynamics on the basis that actin organization is defective in Lowe syndrome fibroblasts (Suchy and Nussbaum, 2002). This effect likely reflects an indirect relationship between ORCL1 and actin dynamics, however. Even subtle derangements in phosphoinositide levels, particularly those of PtdIns-4,5- $\mathrm{P}_{2}$, can upset the delicate homeostatic balance between actin and actin binding proteins -- as occurs in yeast mutants deficient for the Sac1 phosphoinositide phosphatase (Novick et al., 1989; Cleves et al., 1989; Cleves et al., 1991; Whitters et al., 1993). Abnormal $\mathrm{Ca}^{2+}$ signaling may also confuse actin dynamics (Suchy et al., 2009). 


\section{Synaptojanins}

The synaptojanins are dual function Sac-domain phosphatases also evolutionarily conserved from yeast to humans. Synaptojanin 1 was discovered by Pietro De Camilli and colleagues as a nerve terminal protein that functions in synaptic vesicle endocytosis and recycling (McPherson et al., 1994a; McPherson et al., 1994b). This protein is characterized by an Nterminal Sac1-like polyphosphate phosphatase domain which converts PtdIns-3-P, PtdIns-4P, PtdIns-5-P and PtdIns-3,5- $\mathrm{P}_{2}$ to PtdIns, and a central inositol polyphosphate 5-phosphatase domain that hydrolyze phosphoinositides at the D-5 position of the inositol ring (Fig. 5; McPherson et al., 1996; Haffner et al., 1997). The synaptojanin $1 \mathrm{C}$-terminus is subject to modification by alternative splicing programs in adult vs developing neurons, and exhibits a proline-rich region which mediates of synaptojanin 1 interaction with the Src homology 3 (SH3) domains of Grb2 (McPherson et al., 1994a; McPherson et al., 1994b). Grb2 is a 25-kDa adaptor protein with two SH3 domains that flank a Src homology 2 (SH2) domain, and this adaptor is a regulatory component of the synaptic vesicle cycle and neurotransmitter release. Candidate Grb2 effectors include dynamin (a GTPase required for synaptic vesicle endocytosis) and synapsin I -- a synaptic vesicle-associated protein that mediates interaction of synaptic vesicles with the presynaptic cytomatrix (McPherson et al., 1994a).

The synaptojanin 2 catalytic domain is closely related to that of synaptojanin 1 at the primary sequence level, is also a phosphoinositide 5-phosphatase, and displays a broader tissue distribution than synaptojanin 1 . The two synaptojanins exhibit unrelated C-terminal regions, and this property manifests itself in the differential protein-protein interaction spectra of these enzymes (Nemoto et al., 1997; Khvotchev and Südhof, 1998). Whereas synaptojanin 2 binds the SH3 domain containing protein, Grb2, synaptojanin 1 not only binds Grb2, but also amphiphysin and members of SH3p4/8/13 protein family via its C-terminal proline-rich domain (Nemoto et al., 1997). The two synaptojanin isoforms are directed to distinct subcellular locations as a result of their unique sets of protein-protein interactions (Nemoto $e t$ al., 1997).

Synaptojanins 1 and 2 exhibit distinct biological functions. Synaptojanin 1 nullizygous mice survive to term but die shortly after birth. The neonates present neurological defects and accumulate clathrin-coated vesicles at nerve endings, a consequence of impaired turnover of a plasma membrane PtdIns-4,5- $\mathrm{P}_{2}$ pool whose persistence interferes with disassembly of clathrin coats and results in defective synaptic transmission (Cremona et al., 1999; Kim et $a l ., 2002)$. This regulatory function may have other interesting neurological manifestations. The synaptojanin 1 structural gene resides in a genomic region present in trisomic arrangement in Ts65Dn mice, a model for Down's syndrome, and PtdIns-4,5- $\mathrm{P}_{2}$ homeostasis is altered in brains of these mice (Voronov et al., 2008). The neurological and PtdIns-4,5- $\mathrm{P}_{2}$ homeostatic defects that characterize Ts65Dn mice are corrected by restoring synaptojanin 1 structural gene to disomy, and the trisomy of the synaptojanin 1 structural gene alone is sufficient to recapitulate Down's syndrome in mice. Given the human synaptojanin 1 structural gene is located on the trisomic chromosome 21 of human Down's syndrome patients, it is an attractive proposition that increased synaptojanin 1 activity is directly associated with the brain dysfunction and cognitive defects of this disease (Voronov et al., 2008).

Synaptojanin 2 functions in non-neuronal cells by regulating an early step in the clathrinmediated endocytic pathway (Hill et al., 2001; Rusk et al., 2003). Synaptojanin 2 specifically binds the GTP-bound form of the small GTPase Rac1, and overexpression of a membranetargeted version of synaptojanin 2 inhibits endocytosis of epidermal growth factor (EGF) and transferrin receptors (Malecz et al., 2000). Moreover, siRNA experiments demonstrate depletion of synaptojanin 2 (but not synaptojanin 1) compromises clathrin-mediated internalization of EGF receptor and antagonizes formation of clathrin-coated pits and CCVs in lung carcinoma cells (Rusk et al., 2003). The synaptojanin execution point at late stages of 
the secretory pathway, and in endocytosis, is conserved. Dysfunction of the yeast synaptojanin homolog Inp53/Sj13 comprises protein transport from the TGN to endosomes (Ha et al., 2003).

\section{SHIP Polyphosphate 5-Phosphatases}

SHIP1, the prototype for the $\underline{\mathrm{SH}} 2$ domain-containing inositol polyphosphate-5-phosphatases, was discovered in murine hematopoietic cells as a component of a Grb2- and Shc-containing complex (Damen et al., 1996; Kavanaugh et al., 1996; Lioubin et al., 1996). SHIP1 is a 145$\mathrm{KDa}$ protein with an $\mathrm{N}$-terminal SH2 domain, a central catalytic 5-phosphatase domain that contains the two highly conserved signatures of inositol polyphosphate 5-phosphatases, a Cterminal proline-rich region with consensus sites for SH3 domain interactions, and two potential phosphotyrosine binding (PTB) domain-binding sites (NPXY) at the C-terminus (Fig. 5; Damen et al., 1996; Backers et al., 2003). Both humans and rodents also express a related 142-KDa protein (SHIP2) that is widely expressed in different tissues in human with particularly high levels in heart, skeletal muscle and placenta (Pesesse et al., 1997; Pesesse et al., 1998; Ishihara et al., 1999). The domain structure of SHIP2 is similar to that of SHIP1 with the exception that SHIP2 harbors a unique C-terminal sterile alpha motif (SAM) domain which mediates homotypic SAM-domain protein interactions (Fig. 5). Such interactions modulate EphrinA2 receptor internalization and degradation, a process that may also dampen growth factor signaling (Zhuang et al., 2007). SHIP1 and 2 utilize both PtdIns-3,4,5-P $\mathrm{P}_{3}$ and Ins-1,3,4,5$\mathrm{P}_{4}$ as substrates and dephosphorylate these compounds at the D-5 position of the inositol ring (Damen et al., 1996; Pesesse et al., 1998). Kinetic studies report the substrate hierarchy for SHIP2 as Ins-1,2,3,4,5- $\mathrm{P}_{5}>$ Ins-1,3,4,5- $\mathrm{P}_{4}>$ PtdIns-3,4,5- $\mathrm{P}_{3}$. PtdIns-3,5- $\mathrm{P}_{2}$, and the soluble Ins-1,4,5,6- $\mathrm{P}_{4}$, and Ins-2,4,5,6- $\mathrm{P}_{4}$, are utilized as substrates with approximately the same efficiency as PtdIns-3,4,5-P 3 (Chi et al., 2004).

With regard to biological functions, SHIP1 is involved in regulation of the immune response and in survival of myeloid cells while SHIP2 is involved in downregulation of insulin signaling (Huber et al., 1999; Liu et al., 1999; Clement et al., 2001; Sasaoka et al., 2004). Upon growth factor stimulation, SHIP1 translocates from the cytosol to the plasma membrane, and this redistribution is associated with downregulation of signaling via the MAP kinase pathway (Rohrschneider et al., 2000).Similarly, upon insulin stimulation, SHIP2 is redistributed to the plasma membrane with consequent depression of PI3K-dependent insulin signaling resulting from SHIP2-mediated dephosphorylation of PtdIns-3,4,5-P 3 to PtdIns-3,4- $\mathrm{P}_{2}$ (Sasaoka et al., 2004). These data indicate the SHIP1 and SHIP2 enzymes primarily survey agonist-stimulated PtdIns-3,4,5- $\mathrm{P}_{3}$ pools. This is in contrast to PTEN, which accesses both signaling and basal pools of PtdIns-3,4,5- $\mathrm{P}_{3}$ and remains active after long-term stimulation (Stambolic et al., 1998; Liu et al., 1999; Leslie and Downes, 2002; Blero et al., 2005).

\section{Summary}

The evolution of inositol as a compact, yet versatile, signaling scaffold, one subject to positionspecific phosphorylation, has allowed eukaryotes to multiplex the channels of signaling that pass through this simple six-carbon chemical backbone. The intricacies of inositol signaling are accompanied by a correspondingly complex enzymology that governs phosphoinositide synthesis and degradation in a spatially and temporally controlled manner. Degradation of phosphoinositides by phosphatases that do not produce soluble second messenger products is a major pathway for phosphoinositide homeostatic control, as evidenced not only by the number of phosphatases dedicated to phosphoinositide catabolism, but also by the direct linkage of phosphoinositide phosphatase deficiencies to an array of human diseases. From the basic science perspective, the domain arrangements of some phosphoinositide phosphatases are intriguing. For example, why are Sac-domains often physically appended to phosphoinositide 5-phosphate phosphatase catalytic domains? Is this arrangement analogous 
to the interface between phosphoinositide 3-phosphate phosphatases and their catalyticallydead subunits, or does it describe an intimate arrangement for metabolic channeling of substrates? These curious modularities must reflect some fundamental property of these enzymes. Although emerging evidence favors metabolic channeling models (Mani et al., 2007), the nature of that property remains uncertain.

Do phosphoinositide phosphatases play unappreciated roles in promoting signaling? These enzymes degrade phosphoinositides species to other phosphoinositide products that have their own signaling potential after all. How are the phosphatase reactions channeled to prevent precocious activation of signaling? How determining is the mode of phosphoinositide production in terms of signaling outcome (e.g. PtdIns-4-P via action of a PtdIns 4-OH kinase as opposed to degradation of PtdIns-4,5- $\mathrm{P}_{2}$ by a phosphoinositide 5-phosphate phosphatases)? These remain questions for future study.

From the perspective of human disease, the relevance of phosphoinositide phosphatases is established. These disease connections, when coupled with a thorough mechanistic understanding of how phosphoinositide phosphatases function in cells, will further reinforce interest in these enzymes as attractive druggable targets. When the pharmacological encyclopedia of treatment for human diseases is written, we expect that phosphoinositide phosphatases will occupy a significant place in the roster of targets.

\section{Acknowledgments}

We thank Carl Mousley, Phil Majerus, John York and Nick Leslie for helpful discussions and critical input. The authors also thank the reviewers of this manuscript whose suggestions and criticisms greatly improved this review. Work in the authors' laboratory directly relevant to this review was supported by grants NIH R01NS37723 and R01GM44530 awarded to VAB.

\section{References}

Ali IU, Schriml LM, Dean M. Mutational spectra of PTEN/MMAC1 gene: a tumor suppressor with lipid phosphatase activity. J Natl Cancer Inst 1999;91:1922-1932. [PubMed: 10564676]

Astle MV, Seaton G, Davies EM, Fedele CG, Rahman P, Arsala L, Mitchell CA. Regulation of phosphoinositide signaling by the inositol polyphosphate 5-phosphatases. IUBMB Life 2006;58:451456. [PubMed: 16916781]

Atkins MB, et al. Randomized phase II study of multiple dose levels of CCI-779, a novel mammalian target of rapamycin kinase inhibitor, in patients with advanced refractory renal cell carcinoma. J Clin Oncol 2004;22:909-918. [PubMed: 14990647]

Attree O, Olivos IM, Okabe I, Bailey LC, Nelson DL, Lewis RA, McInnes RR, Nussbaum RL. The Lowe's oculocerebrorenal syndrome gene encodes a protein highly homologous to inositol polyphosphate-5-phosphatase. Nature 1992;358:239-242. [PubMed: 1321346]

Audhya A, Foti M, Emr SD. Distinct roles for the yeast phosphatidylinositol 4-kinases, Stt4p and Pik1p, in secretion, cell growth, and organelle membrane dynamics. Mol Biol Cell 2000;11:2673-2689. [PubMed: 10930462]

Backers K, Blero D, Paternotte N, Zhang J, Erneux C. The termination of PI3K signalling by SHIP1 and SHIP2 inositol 5-phosphatases. Adv Enzyme Regul 2003;43:15-28. [PubMed: 12791379]

Bankaitis VA, Aitken JR, Cleves AE, Dowhan W. An essential role for a phospholipid transfer protein in yeast Golgi function. Nature 1990;347:561-562. [PubMed: 2215682]

Begley MJ, Taylor GS, Kim SA, Veine DM, Dixon JE, Stuckey JA. Crystal structure of a phosphoinositide phosphatase, MTMR2: insights into myotubular myopathy and Charcot-MarieTooth syndrome. Mol Cell 2003;12:1391-1402. [PubMed: 14690594]

Berger P, Niemann A, Suter U. Schwann cells and the pathogenesis of inherited motor and sensory neuropathies (Charcot-Marie-Tooth disease). Glia 2006;54:243-257. [PubMed: 16856148] 
Blagoveshchenskaya A, Cheong FY, Rohde HM, Glover G, Knodler A, Nicolson T, Boehmelt G, Mayinger P. Integration of Golgi trafficking and growth factor signaling by the lipid phosphatase SAC1. J Cell Biol 2008;180:803-812. [PubMed: 18299350]

Blero D, Payrastre B, Schurmans S, Erneux C. Phosphoinositide phosphatases in a network of signalling reactions. Pflugers Arch 2007;455:31-44. [PubMed: 17605038]

Blero D, Zhang J, Pesesse X, Payrastre B, Dumont JE, Schurmans S, Erneux C. Phosphatidylinositol 3,4,5-trisphosphate modulation in SHIP2-deficient mouse embryonic fibroblasts. Febs J 2005;272:2512-2522. [PubMed: 15885100]

Blondeau F, Laporte J, Bodin S, Superti-Furga G, Payrastre B, Mandel JL. Myotubularin, a phosphatase deficient in myotubular myopathy, acts on phosphatidylinositol 3-kinase and phosphatidylinositol 3phosphate pathway. Hum Mol Genet 2000;9:2223-2229. [PubMed: 11001925]

Bonangelino CJ, Nau JJ, Duex JE, Brinkman M, Wurmser AE, Gary JD, Emr SD, Weisman LS. Osmotic stress-induced increase of phosphatidylinositol 3,5-bisphosphate requires Vac14p, an activator of the lipid kinase Fab1p. J Cell Biol 2002;156:1015-1028. [PubMed: 11889142]

Bonneau D, Longy M. Mutations of the human PTEN gene. Hum. Mutat 2000;16:109-122. [PubMed: 10923032]

Byrne RD, Garnier-Lhomme M, Han K, Dowicki M, Michael N, Totty N, Zhendre V, Cho A, Pettit TR, Wakelam MJ, Poccia DL, Larijani B. PLCgamma is enriched on poly-phosphoinositide-rich vesicles to control nuclear envelope assembly. Cell Signal 2007;19:913-922. [PubMed: 17184973]

Cantley LC. The phosphoinositide 3-kinase pathway. Science 2002;296:1655-1657. [PubMed: 12040186]

Cantley LC, Neel BG. New insights into tumor suppression: PTEN suppresses tumor formation by restraining the phosphoinositide 3-kinase/AKT pathway. Proc Natl Acad Sci U S A 1999;96:42404245. [PubMed: 10200246]

Cao J, Schulte J, Knight A, Leslie NR, Zagozdzon A, Bronson R, Manevich Y, Beeson C, Neumann CA. Prdx1 inhibits tumorigenesis via regulating PTEN/AKT activity. EMBO J 2009;28:1505-1517. [PubMed: 19369943]

Chan S, et al. Phase II study of temsirolimus (CCI-779), a novel inhibitor of mTOR, in heavily pretreated patients with locally advanced or metastatic breast cancer. J Clin Oncol 2005;23:5314-5322. [PubMed: 15955899]

Chen H, Rossier C, Morris MA, Scott HS, Gos A, Bairoch A, Antonarakis SE. A testis-specific gene, TPTE, encodes a putative transmembrane tyrosine phosphatase and maps to the pericentromeric region of human chromosomes 21 and 13, and to chromosomes 15, 22, and Y. Hum Genet 1999;105:399-409. [PubMed: 10598804]

Chi Y, Zhou B, Wang WQ, Chung SK, Kwon YU, Ahn YH, Chang YT, Tsujishita Y, Hurley JH, Zhang ZY. Comparative mechanistic and substrate specificity study of inositol polyphosphate 5phosphatase Schizosaccharomyces pombe Synaptojanin and SHIP2. J Biol Chem 2004;279:4498744995. [PubMed: 15316017]

Choudhury R, Diao A, Zhang F, Eisenberg E, Saint-Pol A, Williams C, Konstantakopoulos A, Lucocq J, Johannes L, Rabouille C, Greene LE, Lowe M. Lowe syndrome protein OCRL1 interacts with clathrin and regulates protein trafficking between endosomes and the trans-Golgi network. Mol Biol Cell 2005;16:3467-3479. [PubMed: 15917292]

Chow CY, Zhang Y, Dowling JJ, Jin N, Adamska M, Shiga K, Szigeti K, Shy ME, Li J, Zhang X, Lupski JR, Weisman LS, Meisler MH. Mutation of FIG4 causes neurodegeneration in the pale tremor mouse and patients with CMT4J. Nature 2007;448:68-72. [PubMed: 17572665]

Clague MJ, Lorenzo O. The myotubularin family of lipid phosphatases. Traffic 2005;6:1063-1069. [PubMed: 16262718]

Clement S, Krause U, Desmedt F, Tanti JF, Behrends J, Pesesse X, Sasaki T, Penninger J, Doherty M, Malaisse W, Dumont JE, Le Marchand-Brustel Y, Erneux C, Hue L, Schurmans S. The lipid phosphatase SHIP2 controls insulin sensitivity. Nature 2001;409:92-97. [PubMed: 11343120]

Cleves AE, Novick PJ, Bankaitis VA. Mutations in the SAC1 gene suppress defects in yeast Golgi and yeast actin function. J Cell Biol 1989;109:2939-2950. [PubMed: 2687291]

Cleves A, McGee T, Bankaitis V. Phospholipid transfer proteins: a biological debut. Trends Cell Biol 1991;1:30-34. [PubMed: 14731807] 
Cocco L, Gilmour RS, Ognibene A, Letcher AJ, Manzoli FA, Irvine RF. Synthesis of polyphosphoinositides in nuclei of Friend cells. Evidence for polyphosphoinositide metabolism inside the nucleus which changes with cell differentiation. Biochem J 1987;248:765-770. [PubMed: 2829840]

Cockcroft S, De Matteis MA. Inositol lipids as spatial regulators of membrane traffic. J Membr Biol 2001;180:187-194. [PubMed: 11337890]

Coffer PJ, Jin J, Woodgett JR. Protein kinase B (c-Akt): a multifunctional mediator of phosphatidylinositol 3-kinase activation. Biochem J 1998;335(Pt 1):1-13. [PubMed: 9742206]

Cremona O, Di Paolo G, Wenk MR, Luthi A, Kim WT, Takei K, Daniell L, Nemoto Y, Shears SB, Flavell RA, McCormick DA, De Camilli P. Essential role of phosphoinositide metabolism in synaptic vesicle recycling. Cell 1999;99:179-188. [PubMed: 10535736]

Damen JE, Liu L, Rosten P, Humphries RK, Jefferson AB, Majerus PW, Krystal G. The 145-kDa protein induced to associate with Shc by multiple cytokines is an inositol tetraphosphate and phosphatidylinositol 3,4,5-triphosphate 5-phosphatase. Proc Natl Acad Sci U S A 1996;93:16891693. [PubMed: 8643691]

De Matteis MA, Godi A. PI-loting membrane traffic. Nat Cell Biol 2004a;6:487-492. [PubMed: 15170460]

De Matteis MA, Godi A. Protein-lipid interactions in membrane trafficking at the Golgi complex. Biochim Biophys Acta 2004b;1666:264-274. [PubMed: 15519320]

Di Cristofano A, Kotsi P, Peng YF, Cordon-Cardo C, Elkon KB, Pandolfi PP. Impaired Fas response and autoimmunity in Pten+/\#x02212; mice. Science 1999;285:2122-2125. [PubMed: 10497129]

Di Cristofano A, Pesce B, Cordon-Cardo C, Pandolfi PP. Pten is essential for embryonic development and tumour suppression. Nat Genet 1998;19:348-355. [PubMed: 9697695]

Di Paolo G, De Camilli P. Phosphoinositides in cell regulation and membrane dynamics. Nature 2006;443:651-657. [PubMed: 17035995]

Divecha N, Banfić H, Irvine RF. The polyphosphoinositide cycle exists in the nuclei of Swiss 3T3 cells under the control of a receptor (for IGF-I) in the plasma membrane, and stimulation of the cycle increases nuclear diacylglycerol and apparently induces translocation of protein kinase $\mathrm{C}$ to the nucleus. EMBO J 1991;11:3207-3214. [PubMed: 1655412]

Dlakić M. Functionally unrelated signaling proteins contain a fold similar to $\mathrm{Mg}^{2+}$-dependent endonucleases. Trends Biochem Sci 2000;25:272-273. [PubMed: 10838565]

Domin J, Waterfield MD. Using structure to define the function of phosphoinositide 3-kinase family members. FEBS Lett 1997;410:91-95. [PubMed: 9247130]

Dove SK, Cooke FT, Douglas MR, Sayers LG, Parker PJ, Michell RH. Osmotic stress activates phosphatidylinositol-3,5-bisphosphate synthesis. Nature 1997;390:187-192. [PubMed: 9367158]

Downes CP, Ross S, Maccario H, Perera N, Davidson L, Leslie NR. Stimulation of PI 3-kinase signaling via inhibition of the tumor suppressor phosphatase, PTEN. Adv Enzyme Regul 2007;47:184-194. [PubMed: 17343901]

Duex JE, Nau JJ, Kauffman EJ, Weisman LS. Phosphoinositide 5-phosphatase Fig 4p is required for both acute rise and subsequent fall in stress-induced phosphatidylinositol 3,5-bisphosphate levels. Eukaryot Cell 2006a;5:723-731. [PubMed: 16607019]

Duex JE, Tang F, Weisman LS. The Vac14p-Fig4p complex acts independently of Vac7p and couples PI3,5P2 synthesis and turnover. J Cell Biol 2006b;172:693-704. [PubMed: 16492811]

Dyson JM, Kong AM, Wiradjaja F, Astle MV, Gurung R, Mitchell CA. The SH2 domain containing inositol polyphosphate 5-phosphatase-2: SHIP2. Int J Biochem Cell Biol 2005;37:2260-2265. [PubMed: 15964236]

Eberhard DA, Cooper CL, Low MG, Holz RW. Evidence that the inositol phospholipids are necessary for exocytosis. Loss of inositol phospholipids and inhibition of secretion in permeabilized cells caused by a bacterial phospholipase C and removal of ATP. Biochem J 1990;268:15-25. [PubMed: 2160809]

Ellson CD, Anderson KE, Morgan G, Chilvers ER, Lipp P, Stephens LR, Hawkins PT.

Phosphatidylinositol 3-phosphate is generated in phagosomal membranes. Curr Biol 2001;11:16311635. [PubMed: 11676926] 
Erdman S, Lin L, Malczynski M, Snyder M. Pheromone-regulated genes required for yeast mating differentiation. J Cell Biol 1998;140:461-483. [PubMed: 9456310]

Erdmann KS, Mao Y, McCrea HJ, Zoncu R, Lee S, Paradise S, Modregger J, Biemesderfer D, Toomre D, De Camilli P. A role for the lowe syndrome protein OCRL in early steps of the endocytic pathway. Dev Cell 2007;13:377-390. [PubMed: 17765681]

Faucherre A, Desbois P, Nagano F, Satre V, Lunardi J, Gacon G, Dorseuil O. Lowe syndrome protein Ocrl1 is translocated to membrane ruffles upon Rac GTPase activation: a new perspective on Lowe syndrome pathophysiology. Hum Mol Genet 2005;14:1441-1448. [PubMed: 15829501]

Faucherre A, Desbois P, Satre V, Lunardi J, Dorseuil O, Gacon G. Lowe syndrome protein OCRL1 interacts with Rac GTPase in the trans-Golgi network. Hum Mol Genet 2003;12:2449-2456. [PubMed: 12915445]

Faulhammer F, Konrad G, Brankatschk B, Tahirovic S, Knodler A, Mayinger P. Cell growth-dependent coordination of lipid signaling and glycosylation is mediated by interactions between Sac1p and Dpm1p. J Cell Biol 2005;168:185-191. [PubMed: 15657391]

Fauman EB, Saper MA. Structure and function of the protein tyrosine phosphatases. Trends Biochem Sci 1996;21:413-417. [PubMed: 8987394]

Fauman EB, Yuvaniyama C, Schubert HL, Stuckey JA, Saper MA. The X-ray crystal structures of Yersinia tyrosine phosphatase with bound tungstate and nitrate. Mechanistic implications. J Biol Chem 1996;271:18780-18788. [PubMed: 8702535]

Feng Z, Zhang H, Levine AJ, Jin S. The coordinate regulation of the p53 and TOR pathways in cells. Proc Natl Acad Sci U S A 2005;102:8204-8209. [PubMed: 15928081]

Flanagan CA, Schnieders EA, Emerick AW, Kunisawa R, Admon A, Thorner J. Phosphatidylinositol 4kinase: gene structure and requirement for yeast cell viability. Science 1993;262:1444-1448. [PubMed: 8248783]

Foti M, Audhya A, Emr SD. Sac1 lipid phosphatase and Stt4 phosphatidylinositol 4-kinase regulate a pool of phosphatidylinositol 4-phosphate that functions in the control of the actin cytoskeleton and vacuole morphology. Mol Biol Cell 2001;12:2396-2411. [PubMed: 11514624]

Fruman DA, Meyers RE, Cantley LC. Phosphoinositide kinases. Annu Rev Biochem 1998;67:481-507. [PubMed: 9759495]

Garnier-Lhomme M, Byrne RD, Hobday TM, Gschmeissner S, Woscholski R, Poccia DL, Dufourc EJ, Larijani B. Nuclear envelope remnants: fluid membranes enriched in sterols and polyphosphoinositides. PLoS One 2009;4:e4255. [PubMed: 19165341]

Gary JD, Sato TK, Stefan CJ, Bonangelino CJ, Weisman LS, Emr SD. Regulation of Fab1 phosphatidylinositol 3-phosphate 5-kinase pathway by Vac7 protein and Fig4, a polyphosphoinositide phosphatase family member. Mol Biol Cell 2002;13:1238-1251. [PubMed: 11950935]

Goberdhan DC, Paricio N, Goodman EC, Mlodzik M, Wilson C. Drosophila tumor suppressor PTEN controls cell size and number by antagonizing the Chico/PI3-kinase signaling pathway. Genes Dev 1999;13:3244-3258. [PubMed: 10617573]

Goberdhan DC, Wilson C. PTEN: tumour suppressor, multifunctional growth regulator and more. Hum Mol Genet 2003;12(Spec No 2):R239-R248. [PubMed: 12928488]

Godi A, Di Campli A, Konstantakopoulos A, Di Tullio G, Alessi DR, Kular GS, Daniele T, Marra P, Lucocq JM, De Matteis MA. FAPPs control Golgi-to-cell-surface membrane traffic by binding to ARF and PtdIns(4)P. Nat Cell Biol 2004;6:393-404. [PubMed: 15107860]

Gonzales ML, Anderson RA. Nuclear phosphoinositide kinases and inositol phospholipids. J Cell Biochem 2006;97:252-260. [PubMed: 16267839]

Gu J, Tamura M, Pankov R, Danen EH, Takino T, Matsumoto K, Yamada KM. Shc and FAK differentially regulate cell motility and directionality modulated by PTEN. J Cell Biol 1999;146:389403. [PubMed: 10427092]

Gu J, Tamura M, Yamada KM. Tumor suppressor PTEN inhibits integrin- and growth factor-mediated mitogen-activated protein (MAP) kinase signaling pathways. J Cell Biol 1998;143:1375-1383. [PubMed: 9832564] 
Guan KL, Dixon JE. Eukaryotic proteins expressed in Escherichia coli: an improved thrombin cleavage and purification procedure of fusion proteins with glutathione S-transferase. Anal Biochem 1991;192:262-267. [PubMed: 1852137]

Guo S, Stolz LE, Lemrow SM, York JD. SAC1-like domains of yeast SAC1, INP52, and INP53 and of human synaptojanin encode polyphosphoinositide phosphatases. J Biol Chem 1999;274:1299012995. [PubMed: 10224048]

Ha SA, Torabinejad J, DeWald DB, Wenk MR, Lucast L, De Camilli P, Newitt RA, Aebersold R, Nothwehr SF. The synaptojanin-like protein Inp53/Sj13 functions with clathrin in a yeast TGN-toendosome pathway distinct from the GGA protein-dependent pathway. Mol Biol Cell 2003;14:13191333. [PubMed: 12686590]

Haffner C, Takei K, Chen H, Ringstad N, Hudson A, Butler MH, Salcini AE, Di Fiore PP, De Camilli P. Synaptojanin 1: localization on coated endocytic intermediates in nerve terminals and interaction of its $170 \mathrm{kDa}$ isoform with Eps15. FEBS Lett 1997;419:175-180. [PubMed: 9428629]

Hama H, Schnieders EA, Thorner J, Takemoto JY, DeWald DB. Direct involvement of phosphatidylinositol 4-phosphate in secretion in the yeast Saccharomyces cerevisiae. J Biol Chem 1999;274:34294-34300. [PubMed: 10567405]

Han GS, Audhya A, Markley DJ, Emr SD, Carman GM. The Saccharomyces cerevisiae LSB6 gene encodes phosphatidylinositol 4-kinase activity. J Biol Chem 2002;277:47709-47718. [PubMed: 12361950]

Han SY, Kato H, Kato S, Suzuki T, Shibata H, Shiiba K, Matsuno S, Kanamaru R, Ishioka C. Functional evaluation of PTEN missense mutations using in vitro phosphoinositide phosphatase assay. Cancer Res 2000;60:3147-3151. [PubMed: 10866302]

Hay JC, Fisette PL, Jenkins GH, Fukami K, Takenawa T, Anderson RA, Martin TF. ATP-dependent inositide phosphorylation required for $\mathrm{Ca}(2+)$ - activated secretion. Nature 1995;374:173-177. [PubMed: 7877690]

Hay JC, Martin TF. Phosphatidylinositol transfer protein required for ATP-dependent priming of $\mathrm{Ca}(2$ +)-activated secretion. Nature 1993;366:572-575. [PubMed: 8255295]

Hebert DN, Garman SC, Molinari M. The glycan code of the endoplasmic reticulum: asparagine-linked carbohydrates as protein maturation and quality-control tags. Trends Cell Biol 2005;15:364-370. [PubMed: 15939591]

Hill E, van Der Kaay J, Downes CP, Smythe E. The role of dynamin and its binding partners in coated pit invagination and scission. J Cell Biol 2001;152:309-323. [PubMed: 11266448]

Hoopes RR Jr, Shrimpton AE, Knohl SJ, Hueber P, Hoppe B, Matyus J, Simckes A, Tasic V, Toenshoff B, Suchy SF, Nussbaum RL, Scheinman SJ. Dent disease with mutations in OCRL1. Am. J. Hum. Genet 2005;76:260-267. [PubMed: 15627218]

Huber M, Helgason CD, Damen JE, Scheid M, Duronio V, Liu L, Ware MD, Humphries RK, Krystal G. The role of SHIP in growth factor induced signalling. Prog Biophys Mol Biol 1999;71:423-434. [PubMed: 10354708]

Hughes WE, Cooke FT, Parker PJ. Sac phosphatase domain proteins. Biochem J 2000a;350(Pt 2):337352. [PubMed: 10947947]

Hughes WE, Woscholski R, Cooke FT, Patrick RS, Dove SK, McDonald NQ, Parker PJ. SAC1 encodes a regulated lipid phosphoinositide phosphatase, defects in which can be suppressed by the homologous Inp52p and Inp53p phosphatases. J Biol Chem 2000b;275:801-808. [PubMed: 10625610]

Ishihara H, Sasaoka T, Hori H, Wada T, Hirai H, Haruta T, Langlois WJ, Kobayashi M. Molecular cloning of rat SH2-containing inositol phosphatase (SHIP2) and its role in the regulation of insulin signaling. Biochem Biophys Res Commun 1999;260:265-272. [PubMed: 10381377]

Janne PA, Suchy SF, Bernard D, MacDonald M, Crawley J, Grinberg A, Wynshaw-Boris A, Westphal $\mathrm{H}$, Nussbaum RL. Functional overlap between murine Inpp5b and Ocrl1 may explain why deficiency of the murine ortholog for OCRL1 does not cause Lowe syndrome in mice. J Clin Invest 1998;101:2042-2053. [PubMed: 9593760]

Jefferson AB, Majerus PW. Properties of type II inositol polyphosphate 5- phosphatase. J Biol Chem 1995;270:9370-9377. [PubMed: 7721860]

Jin S, Levine AJ. The p53 functional circuit. J. Cell Sci 2001;114:4139-4140. [PubMed: 11739646] 
Jost M, Simpson F, Kavran JM, Lemmon MA, Schmid SL. Phosphatidylinositol-4,5-bisphosphate is required for endocytic coated vesicle formation. Curr Biol 1998;8:1399-1402. [PubMed: 9889104]

Irvine RF. Nuclear lipid signalling. Nat Rev Mol Cell Biol 2003;4:349-360. [PubMed: 12728269]

Irvine RF, Divecha N. Phospholipids in the nucleus--metabolism and possible functions. Semin Cell Biol 1992;3:225-235. [PubMed: 1330068]

Kalthoff C, Groos S, Kohl R, Mahrhold S, Ungewickell EJ. Clint: a novel clathrin-binding ENTH-domain protein at the Golgi. Mol Biol Cell 2002;13:4060-4073. [PubMed: 12429846]

Kavanaugh WM, Pot DA, Chin SM, Deuter-Reinhard M, Jefferson AB, Norris FA, Masiarz FR, Cousens LS, Majerus PW, Williams LT. Multiple forms of an inositol polyphosphate 5-phosphatase form signaling complexes with Shc and Grb2. Curr Biol 1996;6:438-445. [PubMed: 8723348]

Khvotchev M, Südhof TC. Developmentally regulated alternative splicing in a novel synaptojanin. J Biol Chem 1998;273:2306-2311. [PubMed: 9442075]

Kim WT, Chang S, Daniell L, Cremona O, Di Paolo G, De Camilli P. Delayed reentry of recycling vesicles into the fusion-competent synaptic vesicle pool in synaptojanin 1 knockout mice. Proc Natl Acad Sci U S A 2002;99:17143-17148. [PubMed: 12481038]

Kochendörfer KU, Then AR, Kearns BG, Bankaitis VA, Mayinger P. Sac1p plays a crucial role in microsomal ATP transport, which is distinct from its function in Golgi phospholipid metabolism. Embo J 1999;18:1506-1515. [PubMed: 10075922]

Konrad G, Schlecker T, Faulhammer F, Mayinger P. Retention of the yeast Sac1p phosphatase in the endoplasmic reticulum causes distinct changes in cellular phosphoinositide levels and stimulates microsomal ATP transport. J Biol Chem 2002;277:10547-10554. [PubMed: 11792713]

Lad C, Williams NH, Wolfenden R. The rate of hydrolysis of phosphomonoester dianions and the exceptional catalytic proficiencies of protein and inositol phosphatases. Proc Natl Acad Sci U S A 2003;100:5607-5610. [PubMed: 12721374]

Laporte J, Bedez F, Bolino A, Mandel JL. Myotubularins, a large disease-associated family of cooperating catalytically active and inactive phosphoinositides phosphatases. Hum Mol Genet 2003;12(Spec No 2):R285-R292. [PubMed: 12925573]

Laporte J, Hu LJ, Kretz C, Mandel JL, Kioschis P, Coy JF, Klauck SM, Poustka A, Dahl N. A gene mutated in X-linked myotubular myopathy defines a new putative tyrosine phosphatase family conserved in yeast. Nat Genet 1996;13:175-182. [PubMed: 8640223]

Laporte J, Liaubet L, Blondeau F, Tronchere H, Mandel JL, Payrastre B. Functional redundancy in the myotubularin family. Biochem Biophys Res Commun 2002;291:305-312. [PubMed: 11846405]

Larijani B, Poccia DL. Nuclear envelope formation: mind the gaps. Annu Rev Biophys 2009;38:107124. [PubMed: 19416062]

Leahey AM, Charnas LR, Nussbaum RL. Nonsense mutations in the OCRL-1 gene in patients with the oculocerebrorenal syndrome of Lowe. Hum Mol Genet 1993;2:461-463. [PubMed: 8504307]

Lee JO, Yang H, Georgescu MM, Di Cristofano A, Maehama T, Shi Y, Dixon JE, Pandolfi P, Pavletich NP. Crystal structure of the PTEN tumor suppressor: implications for its phosphoinositide phosphatase activity and membrane association. Cell 1999;99:323-334. [PubMed: 10555148]

Lee SH, Jin JB, Song J, Min MK, Park DS, Kim YW, Hwang I. The intermolecular interaction between the $\mathrm{PH}$ domain and the C-terminal domain of Arabidopsis dynamin-like 6 determines lipid binding specificity. J Biol Chem 2002;277:31842-31849. [PubMed: 12105222]

Legendre-Guillemin V, Wasiak S, Hussain NK, Angers A, McPherson PS. ENTH/ANTH proteins and clathrin-mediated membrane budding. J Cell Sci 2004;117:9-18. [PubMed: 14657269]

Lemmon MA. Membrane recognition by phospholipid-binding domains. Nat Rev Mol Cell Biol 2008;9:99-111. [PubMed: 18216767]

Leslie NR, Downes CP. PTEN: The down side of PI 3-kinase signalling. Cell Signal 2002;14:285-295. [PubMed: 11858936]

Leslie NR, Maccario H, Spinelli L, Davidson L. PTEN: The down side of PI 3-kinase signalling. Adv Enz Reg 2009;49 (In Press).

Leslie NR, Yang X, Downes CP, Weijer CJ. PTEN: The down side of PI 3-kinase signalling. Curr Biol 2007;17:115-125. [PubMed: 17240336] 
Levine T, Loewen C. Inter-organelle membrane contact sites: through a glass, darkly. Curr Opin Cell Biol 2006;18:371-378. [PubMed: 16806880]

Levine TP, Munro S. Targeting of Golgi-specific pleckstrin homology domains involves both PtdIns 4kinase-dependent and -independent components. Curr Biol 2002;12:695-704. [PubMed: 12007412]

Li DM, Sun H. TEP1, encoded by a candidate tumor suppressor locus, is a novel protein tyrosine phosphatase regulated by transforming growth factor beta. Cancer Res 1997;57:2124-2129. [PubMed: 9187108]

Li J, Yen C, Liaw D, Podsypanina K, Bose S, Wang SI, Puc J, Miliaresis C, Rodgers L, McCombie R, Bigner SH, Giovanella BC, Ittmann M, Tycko B, Hibshoosh H, Wigler MH, Parsons R. PTEN, a putative protein tyrosine phosphatase gene mutated in human brain, breast, and prostate cancer. Science 1997;275:1943-1947. [PubMed: 9072974]

Li X, Rivas MP, Fang M, Marchena J, Mehrotra B, Chaudhary A, Feng L, Prestwich GD, Bankaitis VA. Analysis of oxysterol binding protein homolog Kes1p function in regulation of Sec14p-dependent protein transport from the yeast Golgi complex. J. Cell Biol 2002;157:63-77. [PubMed: 11916983]

Li X, Routt SM, Xie Z, Cui X, Fang M, Kearns MA, Bard M, Kirsch DR, Bankaitis VA. Identification of a novel family of nonclassic yeast phosphatidylinositol transfer proteins whose function modulates phospholipase D activity and Sec14p-independent cell growth. Mol Biol Cell 2000;11:1989-2005. [PubMed: 10848624]

Liaw D, Marsh DJ, Li J, Dahia PL, Wang SI, Zheng Z, Bose S, Call KM, Tsou HC, Peacocke M, Eng C, Parsons R. Germline mutations of the PTEN gene in Cowden disease, an inherited breast and thyroid cancer syndrome. Nat Genet 1997;16:64-67. [PubMed: 9140396]

Lioubin MN, Algate PA, Tsai S, Carlberg K, Aebersold A, Rohrschneider LR. p150Ship, a signal transduction molecule with inositol polyphosphate-5-phosphatase activity. Genes Dev 1996;10:1084-1095. [PubMed: 8654924]

Liscovitch M, Czarny M, Fiucci G, Tang X. Phospholipase D: molecular and cell biology of a novel gene family. Biochem J 2000;345(Pt 3):401-415. [PubMed: 10642495]

Liu Q, Sasaki T, Kozieradzki I, Wakeham A, Itie A, Dumont DJ, Penninger JM. SHIP is a negative regulator of growth factor receptor-mediated PKB/Akt activation and myeloid cell survival. Genes Dev 1999;13:786-791. [PubMed: 10197978]

Liu Y, Boukhelifa M, Tribble E, Morin-Kensicki E, Uetrecht A, Bear JE, Bankaitis VA. The Sac1 phosphoinositide phosphatase regulates Golgi membrane morphology and mitotic spindle organization in mammals. Mol Biol Cell 2008;19:3080-3096. [PubMed: 18480408]

Loijens JC, Boronenkov IV, Parker GJ, Anderson RA. The phosphatidylinositol 4-phosphate 5-kinase family. Adv Enzyme Regul 1996;36:115-140. [PubMed: 8869744]

Lowe CU, Terrey M, Mac LE. Organic-aciduria, decreased renal ammonia production, hydrophthalmos, and mental retardation; a clinical entity. AMA Am J Dis Child 1952;83:164-184. [PubMed: 14884753]

Lowe M. Structure and function of the Lowe syndrome protein OCRL1. Traffic 2005;6:711-719. [PubMed: 16101675]

Madania A, Dumoulin P, Grava S, Kitamoto H, Scharer-Brodbeck C, Soulard A, Moreau V, Winsor B. The Saccharomyces cerevisiae homolog of human Wiskott-Aldrich syndrome protein Las 17p interacts with the Arp2/3 complex. Mol Biol Cell 1999;10:3521-3538. [PubMed: 10512884]

Maehama T, Dixon JE. The tumor suppressor, PTEN/MMAC1, dephosphorylates the lipid second messenger, phosphatidylinositol 3,4,5-trisphosphate. J Biol Chem 1998;273:13375-13378. [PubMed: 9593664]

Maehama T, Taylor GS, Dixon JE. PTEN and myotubularin: novel phosphoinositide phosphatases. Annu Rev Biochem 2001;70:247-279. [PubMed: 11395408]

Majerus PW, Kisseleva MV, Norris FA. The role of phosphatases in inositol signaling reactions. J Biol Chem 1999;274:10669-10672. [PubMed: 10196133]

Majerus PW, York JD. Phosphoinositide phosphatases and disease. J Lipid Res. 2009

Malecz N, McCabe PC, Spaargaren C, Qiu R, Chuang Y, Symons M. Synaptojanin 2, a novel Rac1 effector that regulates clathrin-mediated endocytosis. Curr Biol 2000;10:1383-1386. [PubMed: 11084340] 
Mani M, Lee SY, Lucast L, Cremona O, Di Paolo G, De Camilli P, Ryan TA. The dual phosphatase activity of synaptojanin 1 is required for both efficient synaptic vesicle endocytosis and reavailability at nerve terminals. Neuron 2007;56:1004-1018. [PubMed: 18093523]

Martelli AM, Follo MY, Evangelisti C, Fala F, Fiume R, Billi AM, Cocco L. Nuclear inositol lipid metabolism: more than just second messenger generation? J Cell Biochem 2005;96:285-292. [PubMed: 16088939]

Martin TF. Phosphoinositide lipids as signaling molecules: common themes for signal transduction, cytoskeletal regulation, and membrane trafficking. Annu Rev Cell Dev Biol 1998;14:231-264. [PubMed: 9891784]

Matzaris M, O'Malley CJ, Badger A, Speed CJ, Bird PI, Mitchell CA. Distinct membrane and cytosolic forms of inositol polyphosphate 5-phosphatase II. Efficient membrane localization requires two discrete domains. J Biol Chem 1998;273:8256-8267. [PubMed: 9525932]

Mayinger P. Regulation of Golgi function via phosphoinositide lipids. Sem. Cell Dev. Biol 2009;20:793800.

McCrea HJ, Paradise S, Tomasini L, Addis M, Melis MA, De Matteis MA, De Camilli P. All known patient mutations in the ASH-RhoGAP domains of OCRL affect targeting and APPL1 binding. Biochem Biophys Res Commun 2008;369:493-499. [PubMed: 18307981]

McPherson PS, Czernik AJ, Chilcote TJ, Onofri F, Benfenati F, Greengard P, Schlessinger J, De Camilli P. Interaction of Grb2 via its Src homology 3 domains with synaptic proteins including synapsin I. Proc Natl Acad Sci U S A 1994a;91:6486-6490. [PubMed: 8022809]

McPherson PS, Garcia EP, Slepnev VI, David C, Zhang X, Grabs D, Sossin WS, Bauerfeind R, Nemoto Y, De Camilli P. A presynaptic inositol-5-phosphatase. Nature 1996;379:353-357. [PubMed: 8552192]

McPherson PS, Takei K, Schmid SL, De Camilli P. p145, a major Grb2-binding protein in brain, is colocalized with dynamin in nerve terminals where it undergoes activity-dependent dephosphorylation. J Biol Chem 1994b;269:30132-30139. [PubMed: 7982917]

Mercer JA, Seperack PK, Strobel MC, Copeland NG, Jenkins NA. Novel myosin heavy chain encoded by murine dilute color locus. Nature 1991;349:709-713. [PubMed: 1996138]

Meusser B, Hirsch C, Jarosch E, Sommer T. ERAD: the long road to destruction. Nat. Cell Biol 2005;7:766-772. [PubMed: 16056268]

Michell RH, Dove SK. A protein complex that regulates PtdIns(3,5)P 2 levels. Embo J 2009;28:86-87. [PubMed: 19158662]

Michell RH, Heath VL, Lemmon MA, Dove SK. Phosphatidylinositol 3,5-bisphosphate: metabolism and cellular functions. Trends Biochem Sci 2006;31:52-63. [PubMed: 16364647]

Mills IG, Praefcke GJ, Vallis Y, Peter BJ, Olesen LE, Gallop JL, Butler PJ, Evans PR, McMahon HT. EpsinR: an AP1/clathrin interacting protein involved in vesicle trafficking. J Cell Biol 2003;160:213-222. [PubMed: 12538641]

Mitchell CA, Brown S, Campbell JK, Munday AD, Speed CJ. Regulation of second messengers by the inositol polyphosphate 5-phosphatases. Biochem Soc Trans 1996;24:994-1000. [PubMed: 8968499]

Mochizuki Y, Majerus PW. Characterization of myotubularin-related protein 7 and its binding partner, myotubularin-related protein 9. Proc Natl Acad Sci U S A 2003;100:9768-9773. [PubMed: 12890864]

Myers MP, Pass I, Batty IH, Van der Kaay J, Stolarov JP, Hemmings BA, Wigler MH, Downes CP, Tonks NK. The lipid phosphatase activity of PTEN is critical for its tumor supressor function. Proc Natl Acad Sci U S A 1998;95:13513-13518. [PubMed: 9811831]

Myers MP, Stolarov JP, Eng C, Li J, Wang SI, Wigler MH, Parsons R, Tonks NK. P-TEN, the tumor suppressor from human chromosome 10q23, is a dual-specificity phosphatase. Proc Natl Acad Sci U S A 1997;94:9052-9057. [PubMed: 9256433]

Nelen MR, van Staveren WC, Peeters EA, Hassel MB, Gorlin RJ, Hamm H, Lindboe CF, Fryns JP, Sijmons RH, Woods DG, Mariman EC, Padberg GW, Kremer H. Germline mutations in the PTEN/ MMAC1 gene in patients with Cowden disease. Hum Mol Genet 1997;6:1383-1387. [PubMed: 9259288] 
Nemoto Y, Arribas M, Haffner C, DeCamilli P. Synaptojanin 2, a novel synaptojanin isoform with a distinct targeting domain and expression pattern. J Biol Chem 1997;272:30817-30821. [PubMed: 9388224]

Nemoto Y, Kearns BG, Wenk MR, Chen H, Mori K, Alb JG Jr, De Camilli P, Bankaitis VA. Functional characterization of a mammalian Sac1 and mutants exhibiting substrate-specific defects in phosphoinositide phosphatase activity. J Biol Chem 2000;275:34293-34305. [PubMed: 10887188]

Nicot AS, Laporte J. Endosomal phosphoinositides and human diseases. Traffic 2008;9:1240-1249. [PubMed: 18429927]

Norris FA, Atkins RC, Majerus PW. The cDNA cloning and characterization of inositol polyphosphate 4-phosphatase type II. Evidence for conserved alternative splicing in the 4-phosphatase family. J. Biol. Chem 1997;272:23859-23864. [PubMed: 9295334]

Novick P, Osmond BC, Botstein D. Suppressors of yeast actin mutations. Genetics 1989;121:659-674. [PubMed: 2656401]

Nystuen A, Legare ME, Schultz LD, Frankel WN. A null mutation in inositol polyphosphate 4phosphatase type I causes selective neuronal loss in weeble mutant mice. Neuron 2001;32:203212. [PubMed: 11683991]

Olivos-Glander IM, Janne PA, Nussbaum RL. The oculocerebrorenal syndrome gene product is a 105$\mathrm{kD}$ protein localized to the Golgi complex. Am J Hum Genet 1995;57:817-823. [PubMed: 7573041]

Ooms LM, Horan KA, Rahman P, Seaton G, Gurung R, Kethesparan DS, Mitchell CA. The role of the inositol polyphosphate 5-phosphatases in cellular function and human disease. Biochem J 2009;419:29-49. [PubMed: 19272022]

Podsypanina K, et al. An inhibitor of mTOR reduces neoplasia and normalizes p70/S6 kinase activity in Pten+/- mice. Proc Natl Acad Sci USA 2001;98:10320-10325. [PubMed: 11504907]

Peretti D, Dahan N, Shimoni E, Hirschberg K, Lev S. Coordinated lipid transfer between the endoplasmic reticulum and the Golgi complex requires the VAP proteins and is essential for Golgi-mediated transport. Mol Biol Cell 2008;19:3871-3884. [PubMed: 18614794]

Pesesse X, Deleu S, De Smedt F, Drayer L, Erneux C. Identification of a second SH2-domain-containing protein closely related to the phosphatidylinositol polyphosphate 5-phosphatase SHIP. Biochem Biophys Res Commun 1997;239:697-700. [PubMed: 9367831]

Pesesse X, Moreau C, Drayer AL, Woscholski R, Parker P, Erneux C. The SH2 domain containing inositol 5-phosphatase SHIP2 displays phosphatidylinositol 3,4,5-trisphosphate and inositol 1,3,4,5tetrakisphosphate 5-phosphatase activity. FEBS Lett 1998;437:301-303. [PubMed: 9824312]

Pichler H, Gaigg B, Hrastnik C, Achleitner G, Kohlwein SD, Zellnig G, Perktold A, Daum G. A subfraction of the yeast endoplasmic reticulum associates with the plasma membrane and has a high capacity to synthesize lipids. Eur J Biochem 2001;268:2351-2361. [PubMed: 11298754]

Quattrone A, Gambardella A, Bono F, Aguglia U, Bolino A, Bruni AC, Montesi MP, Oliveri RL, Sabatelli M, Tamburrini O, Valentino P, Van Broeckhoven C, Zappia M. Autosomal recessive hereditary motor and sensory neuropathy with focally folded myelin sheaths: clinical, electrophysiologic, and genetic aspects of a large family. Neurology 1996;46:1318-1324. [PubMed: 8628474]

Raftopolou M, Etienne-Manneville S, Self A, Nicholls S, Hall A. Regulation of cell migration by the C2 domain of the tumour suppressor PTEN. Science 2004;303:1179-1181. [PubMed: 14976311]

Rameh LE, Cantley LC. The role of phosphoinositide 3-kinase lipid products in cell function. J Biol Chem 1999;274:8347-8350. [PubMed: 10085060]

Rameh LE, Tolias KF, Duckworth BC, Cantley LC. A new pathway for synthesis of phosphatidylinositol-4,5-bisphosphate. Nature 1997;390:192-193. [PubMed: 9367159]

Ramjaun AR, McPherson PS. Tissue-specific alternative splicing generates two synaptojanin isoforms with differential membrane binding properties. J Biol Chem 1996;271:24856-24861. [PubMed: 8798761]

Rebecchi MJ, Pentyala SN. Structure, function, and control of phosphoinositide-specific phospholipase C. Physiol Rev 2000;80:1291-1335. [PubMed: 11015615]

Rivas MP, Kearns BG, Xie Z, Guo S, Sekar MC, Hosaka K, Kagiwada S, York JD, Bankaitis VA. Pleiotropic alterations in lipid metabolism in yeast sac1 mutants: relationship to "bypass Sec14p" and inositol auxotrophy. Mol Biol Cell 1999;10:2235-2250. [PubMed: 10397762] 
Robinson FL, Dixon JE. Myotubularin phosphatases: policing 3-phosphoinositides. Trends Cell Biol 2006;16:403-412. [PubMed: 16828287]

Rohde HM, Cheong FY, Konrad G, Paiha K, Mayinger P, Boehmelt G. The human phosphatidylinositol phosphatase SAC1 interacts with the coatomer I complex. J Biol Chem 2003;278:52689-52699. [PubMed: 14527956]

Rohrschneider LR, Fuller JF, Wolf I, Liu Y, Lucas DM. Structure, function, and biology of SHIP proteins. Genes Dev 2000;14:505-520. [PubMed: 10716940]

Roth MG. Phosphoinositides in constitutive membrane traffic. Physiol Rev 2004;84:699-730. [PubMed: 15269334]

Routt SM, Ryan MM, Tyeryar K, Rizzieri KE, Mousley C, Roumanie O, Brennwald PJ, Bankaitis VA. Nonclassical PITPs activate PLD via the Stt4p PtdIns-4-kinase and modulate function of late stages of exocytosis in vegetative yeast. Traffic 2005;6:1157-1172. [PubMed: 16262726]

Roy A, Levine TP. Multiple pools of phosphatidylinositol 4-phosphate detected using the pleckstrin homology domain of Osh2p. J Biol Chem 2004;279:44683-44689. [PubMed: 15271978]

Rudge SA, Anderson DM, Emr SD. Vacuole size control: regulation of PtdIns(3,5)P2 levels by the vacuole-associated Vac14-Fig4 complex, a PtdIns(3,5)P2-specific phosphatase. Mol Biol Cell 2004;15:24-36. [PubMed: 14528018]

Rusk N, Le PU, Mariggio S, Guay G, Lurisci C, Nabi IR, Corda D, Symons M. Synaptojanin 2 functions at an early step of clathrin-mediated endocytosis. Curr Biol 2003;13:659-663. [PubMed: 12699622]

Sasaoka T, Wada T, Fukui K, Murakami S, Ishihara H, Suzuki R, Tobe K, Kadowaki T, Kobayashi M. $\mathrm{SH} 2$-containing inositol phosphatase 2 predominantly regulates Akt2, and not Akt1, phosphorylation at the plasma membrane in response to insulin in 3T3-L1 adipocytes. J Biol Chem 2004;279:14835-14843. [PubMed: 14744864]

Schmid AC, Wise HM, Mitchell CA, Nussbaum R, Woscholski R. Type II phosphoinositide 5phosphatases have unique sensitivities towards fatty acid composition and head group phosphorylation. FEBS Lett 2004;576:9-13. [PubMed: 15474001]

Schu PV, Takegawa K, Fry MJ, Stack JH, Waterfield MD, Emr SD. Phosphatidylinositol 3-kinase encoded by yeast VPS34 gene essential for protein sorting. Science 1993;260:88-91. [PubMed: 8385367]

Shin HW, Hayashi M, Christoforidis S, Lacas-Gervais S, Hoepfner S, Wenk MR, Modregger J, Uttenweiler-Joseph S, Wilm M, Nystuen A, Frankel WN, Solimena M, DeCamilli P, Zerial M. An enzymatic cascade of Rab5 effectors regulates phosphoinositide turnover in the endocytic pathway. J Cell Biol 2005;170:607-618. [PubMed: 16103228]

Shisheva A. PIKfyve: the road to PtdIns 5-P and PtdIns 3,5-P(2). Cell Biol Int 2001;25:1201-1206. [PubMed: 11748912]

Simpson L, Parsons R. PTEN: life as a tumor suppressor. Exp Cell Res 2001;264:29-41. [PubMed: 11237521]

Singer WD, Brown HA, Sternweis PC. Regulation of eukaryotic phosphatidylinositol-specific phospholipase C and phospholipase D. Annu Rev Biochem 1997;66:475-509. [PubMed: 9242915]

Speed CJ, Matzaris M, Bird PI, Mitchell CA. Tissue distribution and intracellular localisation of the 75kDa inositol polyphosphate 5-phosphatase. Eur J Biochem 1995;234:216-224. [PubMed: 8529643]

Srinivasan S, Seaman M, Nemoto Y, Daniell L, Suchy SF, Emr S, De Camilli P, Nussbaum R. Disruption of three phosphatidylinositol-polyphosphate 5-phosphatase genes from Saccharomyces cerevisiae results in pleiotropic abnormalities of vacuole morphology, cell shape, and osmohomeostasis. Eur J Cell Biol 1997;74:350-360. [PubMed: 9438131]

Stambolic V, MacPherson D, Sas D, Lin Y, Snow B, Jang Y, Benchimol S, Mak TW. Regulation of PTEN transcription by p53. Mol. Cell 2001:317-325. [PubMed: 11545734]

Stambolic V, Suzuki A, de la Pompa JL, Brothers GM, Mirtsos C, Sasaki T, Ruland J, Penninger JM, Siderovski DP, Mak TW. Negative regulation of PKB/Akt-dependent cell survival by the tumor suppressor PTENC. Cell 1998;95:29-39. [PubMed: 9778245]

Stambolic V, Tsao MS, Macpherson D, Suzuki A, Chapman WB, Mak TW. High incidence of breast and endometrial neoplasia resembling human Cowden syndrome in pten $+/-$ mice. Cancer Res 2000;60:3605-3611. [PubMed: 10910075] 
Steck PA, Pershouse MA, Jasser SA, Yung WK, Lin H, Ligon AH, Langford LA, Baumgard ML, Hattier T, Davis T, Frye C, Hu R, Swedlund B, Teng DH, Tavtigian SV. Identification of a candidate tumour suppressor gene, MMAC1, at chromosome 10q23.3 that is mutated in multiple advanced cancers. Nat Genet 1997;15:356-362. [PubMed: 9090379]

Stefan CJ, Audhya A, Emr SD. The yeast synaptojanin-like proteins control the cellular distribution of phosphatidylinositol (4,5)-bisphosphate. Mol Biol Cell 2002;13:542-557. [PubMed: 11854411]

Stiles B, Groszer M, Wang S, Jiao J, Wu H. PTENless means more. Dev Biol 2004;273:175-184. [PubMed: 15328005]

Stocker H, Andjelkovic M, Oldham S, Laffargue M, Wymann MP, Hemmings BA, Hafen E. Living with lethal $\mathrm{PIP}_{3}$ levels: viability of flies lacking PTEN restored by a PH domain mutation in Akt/PKB. Science 2002;295:2088-2091. [PubMed: 11872800]

Stolz LE, Kuo WJ, Longchamps J, Sekhon MK, York JD. INP51, a yeast inositol polyphosphate 5phosphatase required for phosphatidylinositol 4,5-bisphosphate homeostasis and whose absence confers a cold-resistant phenotype. J Biol Chem 1998;273:11852-11861. [PubMed: 9565610]

Strahl T, Thorner J. Synthesis and function of membrane phosphoinositides in budding yeast, Saccharomyces cerevisiae. Biochim Biophys Acta 2007;1771:353-404. [PubMed: 17382260]

Suchy SF, Nussbaum RL. The deficiency of $\mathrm{PIP}_{2}$ 5-phosphatase in Lowe syndrome affects actin polymerization. Am J Hum Genet 2002;71:1420-1427. [PubMed: 12428211]

Suchy SF, Cronin JC, Nussbaum RL. Abnormal bradykinin signalling in fibroblasts deficient in the $\mathrm{PIP}_{2}$ 5-phosphatase, ocrl1. J Inherit Metab Dis 2009;32:280-288. [PubMed: 19172411]

Sun H, Lesche R, Li DM, Liliental J, Zhang H, Gao J, Gavrilova N, Mueller B, Liu X, Wu H. PTEN modulates cell cycle progression and cell survival by regulating phosphatidylinositol 3,4,5,trisphosphate and Akt/protein kinase B signaling pathway. Proc Natl Acad Sci U S A 1999;96:6199_ 6204. [PubMed: 10339565]

Suzuki A, Nakano T, Mak TW, Sasaki T. Portrait of PTEN: messages from mutant mice. Cancer Sci 2008;99:209-213. [PubMed: 18201277]

Taylor GS, Dixon JE. PTEN and myotubularins: families of phosphoinositide phosphatases. Methods Enzymol 2003;366:43-56. [PubMed: 14674238]

Taylor GS, Maehama T, Dixon JE. Inaugural article: myotubularin, a protein tyrosine phosphatase mutated in myotubular myopathy, dephosphorylates the lipid second messenger, phosphatidylinositol 3-phosphate. Proc Natl Acad Sci U S A 2000;97:8910-8915. [PubMed: 10900271]

Tronchere H, Buj-Bello A, Mandel JL, Payrastre B. Implication of phosphoinositide phosphatases in genetic diseases: the case of myotubularin. Cell Mol Life Sci 2003;60:2084-2099. [PubMed: 14618257]

Tronchere H, Laporte J, Pendaries C, Chaussade C, Liaubet L, Pirola L, Mandel JL, Payrastre B. Production of phosphatidylinositol 5-phosphate by the phosphoinositide 3-phosphatase myotubularin in mammalian cells. J Biol Chem 2004;279:7304-7312. [PubMed: 14660569]

Ungewickell A, Ward ME, Ungewickell E, Majerus PW. The inositol polyphosphate 5-phosphatase Ocrl associates with endosomes that are partially coated with clathrin. Proc Natl Acad Sci U S A 2004;101:13501-13506. [PubMed: 15353600]

Van Diepen MT, Parsons M, Downes CP, Leslie NR, Hindges R, Eickholt BJ. MyosinV controls PTEN function and neuronal cell size. Nature Cell Biol 2009;11:1191-1196. [PubMed: 19767745]

van Rheenen J, Jalink K. Agonist-induced PIP 2 hydrolysis inhibits cortical actin dynamics: regulation at a global but not at a micrometer scale. Mol Biol Cell 2002;13:3257-3267. [PubMed: 12221130]

Vazquez F, Grossman SR, Takahashi Y, Rokas MV, Nakamura N, Sellers WR. Phosphorylation of the PTEN tail acts as an inhibitory switch by preventing its recruitment into a protein complex. J Biol Chem 2001;276:48627-48630. [PubMed: 11707428]

Vazquez F, Ramaswamy S, Nakamura N, Sellers WR. Phosphorylation of the PTEN tail regulates protein stability and function. Mol Cell Biol 2001;20:5010-5018. [PubMed: 10866658]

Vicinanza M, D'Angelo G, Di Campli A, De Matteis MA. Function and dysfunction of the PI system in membrane trafficking. Embo J 2008;27:2457-2470. [PubMed: 18784754]

Prog Lipid Res. Author manuscript; available in PMC 2011 July 1. 
Vogelmann R, Nguyen-Tat MD, Giehl K, Adler G, Wedlich D, Menke A. A TGFbeta-induced downregulation of E-cadherin-based cell-cell adhesion depends on PI3-kinase and PTEN. J Cell Sci 2005;118:4901-4912. [PubMed: 16219695]

Von Stein W, Ramrath A, Grimm A, Muller-Borg M, Wodarz A. Direct association of Bazooka/Par-3 with the lipid phosphatase PTEN reveals a link between the PAR/aPKC complex and phosphoinositide signaling. Development 2005;132:1675-1686. [PubMed: 15743877]

Voronov SV, Frere SG, Giovedi S, Pollina EA, Borel C, Zhang H, Schmidt C, Akeson EC, Wenk MR, Cimasoni L, Arancio O, Davisson MT, Antonarakis SE, Gardiner K, De Camilli P, Di Paolo G. Synaptojanin 1-linked phosphoinositide dyshomeostasis and cognitive deficits in mouse models of Down's syndrome. Proc Natl Acad Sci U S A 2008;105:9415-9420. [PubMed: 18591654]

Walker SM, Downes CP, Leslie NR. TPIP: a novel phosphoinositide 3-phosphatase. Biochem J 2001;360:277-283. [PubMed: 11716755]

Wang YJ, Wang J, Sun HQ, Martinez M, Sun YX, Macia E, Kirchhausen T, Albanesi JP, Roth MG, Yin HL. Phosphatidylinositol 4 phosphate regulates targeting of clathrin adaptor AP-1 complexes to the Golgi. Cell 2003;114:299-310. [PubMed: 12914695]

Waselle L, Gerona RR, Vitale N, Martin TF, Bader MF, Regazzi R. Role of phosphoinositide signaling in the control of insulin exocytosis. Mol Endocrinol 2005;19:3097-3106. [PubMed: 16081518]

Watt SA, Kular G, Fleming IN, Downes CP, Lucocq JM. Subcellular localization of phosphatidylinositol 4,5-bisphosphate using the pleckstrin homology domain of phospholipase C delta1. Biochem $\mathrm{J}$ 2002;363:657-666. [PubMed: 11964166]

Way G, O'Luanaigh N, Cockcroft S. Activation of exocytosis by cross-linking of the IgE receptor is dependent on ADP-ribosylation factor 1-regulated phospholipase D in RBL-2H3 mast cells: evidence that the mechanism of activation is via regulation of phosphatidylinositol 4,5-bisphosphate synthesis. Biochem J 2000;346(Pt 1):63-70. [PubMed: 10657240]

Wei H-C, Sanny J, Shu H, Baille DL, Brill JA, Price JV, Harden N. The Sac1 lipid phosphatase regulates cell shape change and JNK cascade during dorsal closure in Drosophila. Curr Biol 2003;13:18821887. [PubMed: 14588244]

Wendel HG, et al. Survival signalling by Akt and eIF4E in oncogenesis and cancer therapy. Nature 2004;428:332-337. [PubMed: 15029198]

Whisstock JC, Romero S, Gurung R, Nandurkar H, Ooms LM, Bottomley SP, Mitchell CA. The inositol polyphosphate 5-phosphatases and the apurinic/apyrimidinic base excision repair endonuclease share a common mechanism for catalysis. J. Biol. Chem 2000;47:37055-37061. [PubMed: 10962003]

Whisstock JC, Wiradjaja F, Waters JE, Gurung R. The structure and function of catalytic domains within inositol polyphosphate 5-phosphatases. IUBMB Life 2002;53:15-23. [PubMed: 12018403]

Whitters EA, Cleves AE, McGee TP, Skinner HB, Bankaitis VA. SAC1p is an integral membrane protein that influences the cellular requirement for phospholipid transfer protein function and inositol in yeast. J Cell Biol 1993;122:79-94. [PubMed: 8314848]

Wishart MJ, Taylor GS, Slama JT, Dixon JE. PTEN and myotubularin phosphoinositide phosphatases: bringing bioinformatics to the lab bench. Curr Opin Cell Biol 2001;13:172-181. [PubMed: 11248551]

Woods CS, Schmitz KR, Bessman NJ, Setty TG, Ferguson KM, Burd CG. PtdIns4P recognition by Vps74/GOLPH3 links PtdIns 4-kinase signaling to retrograde Golgi trafficking. J Cell Biol. 2009 (In Press).

Wu Y, Dowbenko D, Spencer S, Laura R, Lee J, Gu Q, Lasky LA. Interaction of the tumor suppressor PTEN/MMAC with a PDZ domain of MAGI3, a novel membrane-associated guanylate kinase. J Biol Chem 2000;275:21477-21485. [PubMed: 10748157]

Xie Z, Fang M, Bankaitis VA. Evidence for an intrinsic toxicity of phosphatidylcholine to Sec14pdependent protein transport from the yeast Golgi complex. Mol Biol Cell 2001;12:1117-1129. [PubMed: 11294911]

Yamada KM, Araki M. Tumor suppressor PTEN: modulator of cell signaling, growth, migration and apoptosis. J Cell Sci 2001;114:2375-2382. [PubMed: 11559746] 
Yamamoto A, DeWald DB, Boronenkov IV, Anderson RA, Emr SD, Koshland D. Novel PI(4)P 5-kinase homolog, Fab1p, essential for normal vacuole function and morphology in yeast. Mol Biol Cell 1995;6:525-539. [PubMed: 7663021]

Yoshida S, Ohya Y, Goebl M, Nakano A, Anraku Y. A novel gene, STT4, encodes a phosphatidylinositol 4-kinase in the PKC1 protein kinase pathway of Saccharomyces cerevisiae. J Biol Chem 1994a; 269:1166-1172. [PubMed: 8288577]

Yoshida S, Ohya Y, Nakano A, Anraku Y. Genetic interactions among genes involved in the STT4-PKC1 pathway of Saccharomyces cerevisiae. Mol Gen Genet 1994b;242:631-640. [PubMed: 8152413]

Zhang X, Hartz PA, Philip E, Racusen LC, Majerus PW. Cell lines from kidney proximal tubules of a patient with Lowe syndrome lack OCRL inositol polyphosphate 5-phosphatase and accumulate phosphatidylinositol 4,5-bisphosphate. J Biol Chem 1998;273:1574-1582. [PubMed: 9430698]

Zhang X, Jefferson AB, Auethavekiat V, Majerus PW. The protein deficient in Lowe syndrome is a phosphatidylinositol-4,5-bisphosphate 5-phosphatase. Proc Natl Acad Sci U S A 1995;92:48534856. [PubMed: 7761412]

Zhao R, Qi Y, Chen J, Zhao ZJ. FYVE-DSP2, a FYVE domain-containing dual specificity protein phosphatase that dephosphorylates phosphotidylinositol 3-phosphate. Exp Cell Res 2001;265:329338. [PubMed: 11302699]

Zhuang G, Hunter S, Hwang Y, Chen J. Regulation of EphA2 receptor endocytosis by SHIP2 lipid phosphatase via phosphatidylinositol 3-Kinase-dependent Rac1 activation. J Biol Chem 2007;282:2683-2694. [PubMed: 17135240]

Zvelebil MJ, MacDougall L, Leevers S, Volinia S, Vanhaesebroeck B, Gout I, Panayotou G, Domin J, Stein R, Pages F, et al. Structural and functional diversity of phosphoinositide 3-kinases. Philos Trans R Soc Lond B Biol Sci 1996;351:217-223. [PubMed: 8650269] 


\section{Outer/lumenal leaflet}

\section{Fatty acid chains}

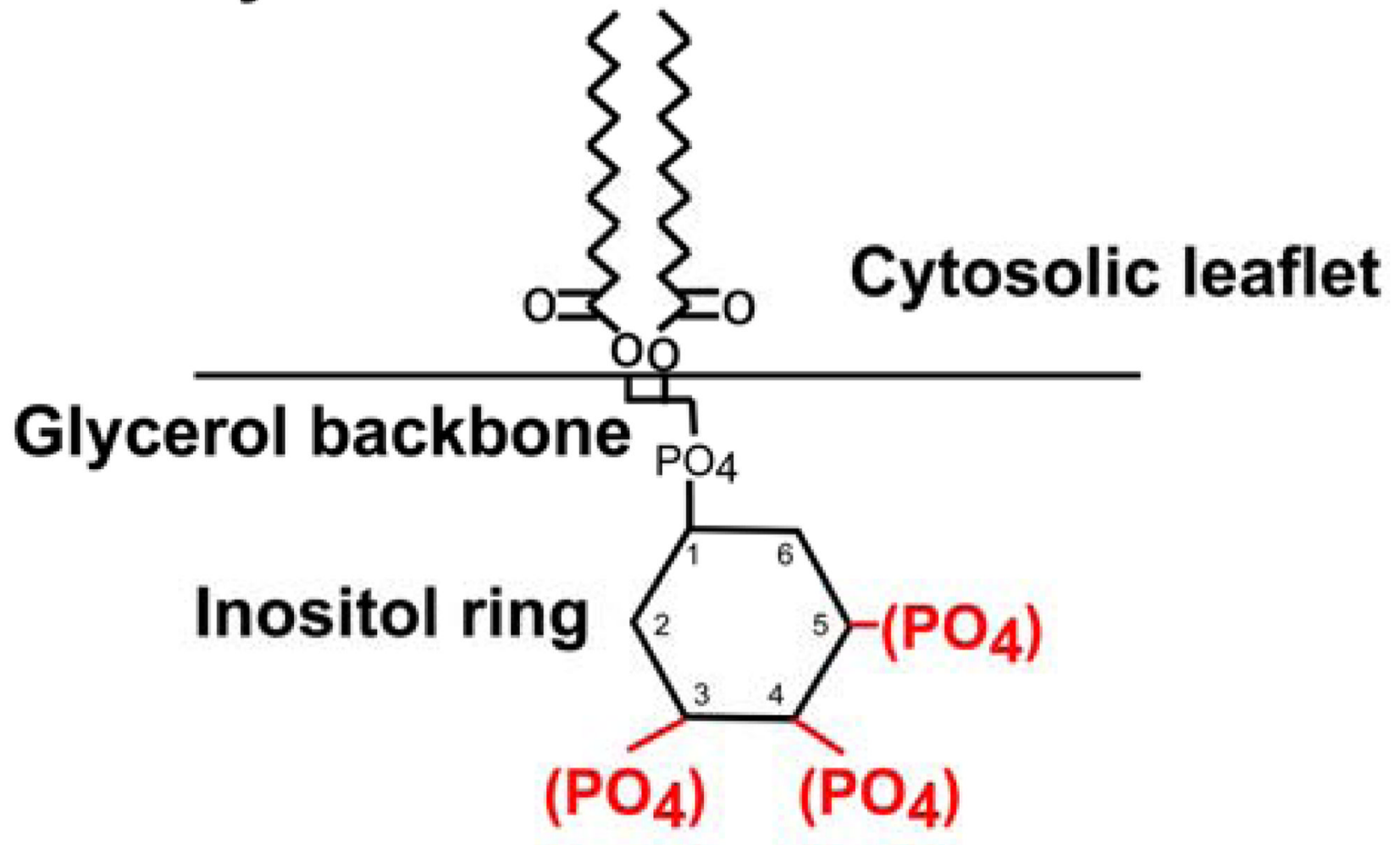

Figure 1.

Phosphoinositides are phosphorylated derivatives of PtdIns. The chemical structures of PtdIns and Phosphoinositides are shown highlighting the inositol headgroup, glycerol backbone and two fatty acyl chains. The inositol headgroup can be combinatorially phosphorylated at the $\mathrm{D}-3 \mathrm{OH},-4 \mathrm{OH},-5 \mathrm{OH}$ positions of the inositol ring as indicated in red. 


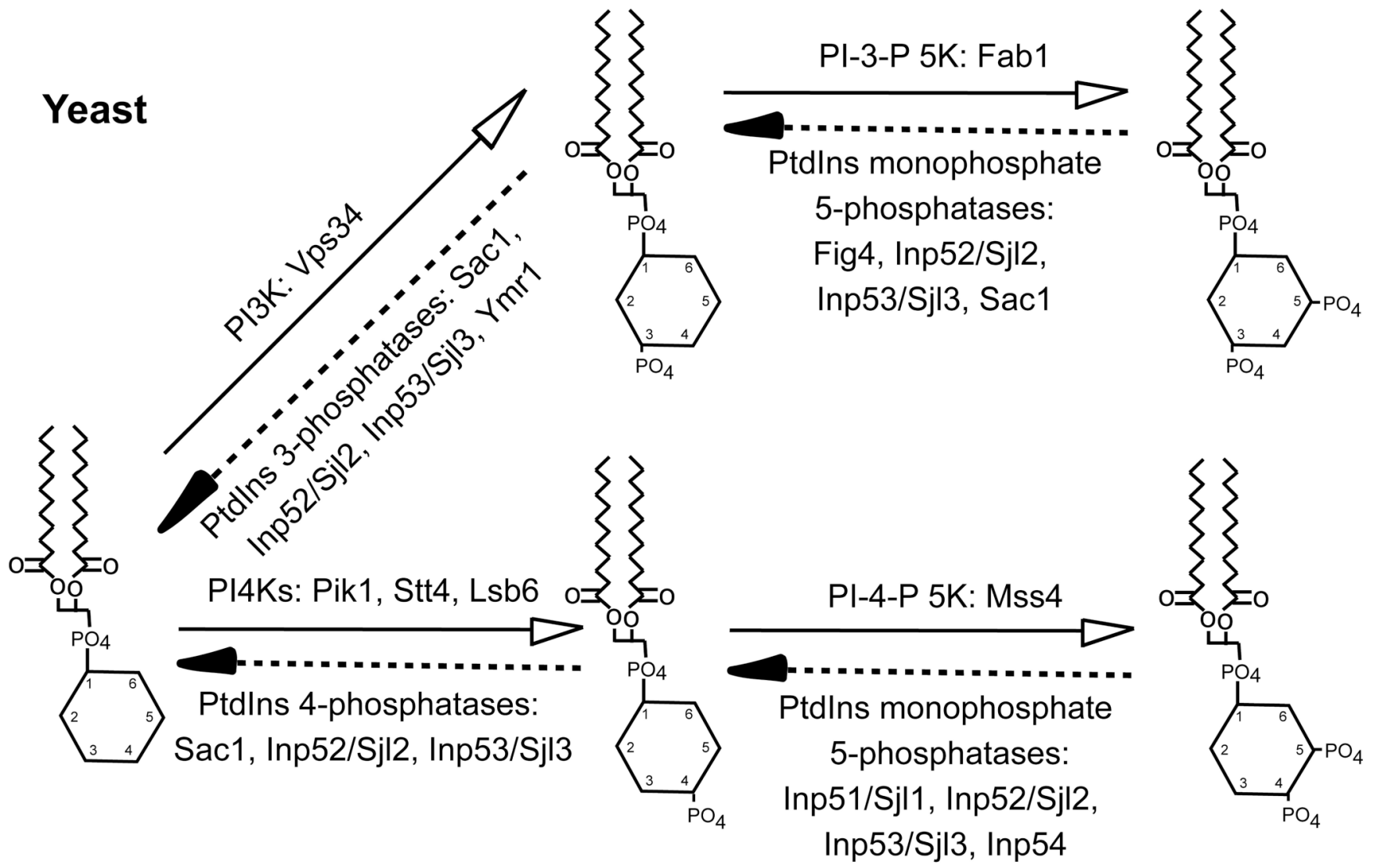

Figure 2.

Phosphoinositide metabolism in the yeast Saccharomyces cerevisiae. The execution points of the yeast PtdIns kinases and phosphoinositide phosphatases that regulate the synthesis and turnover of phosphoinositides, respectively, are identified. 


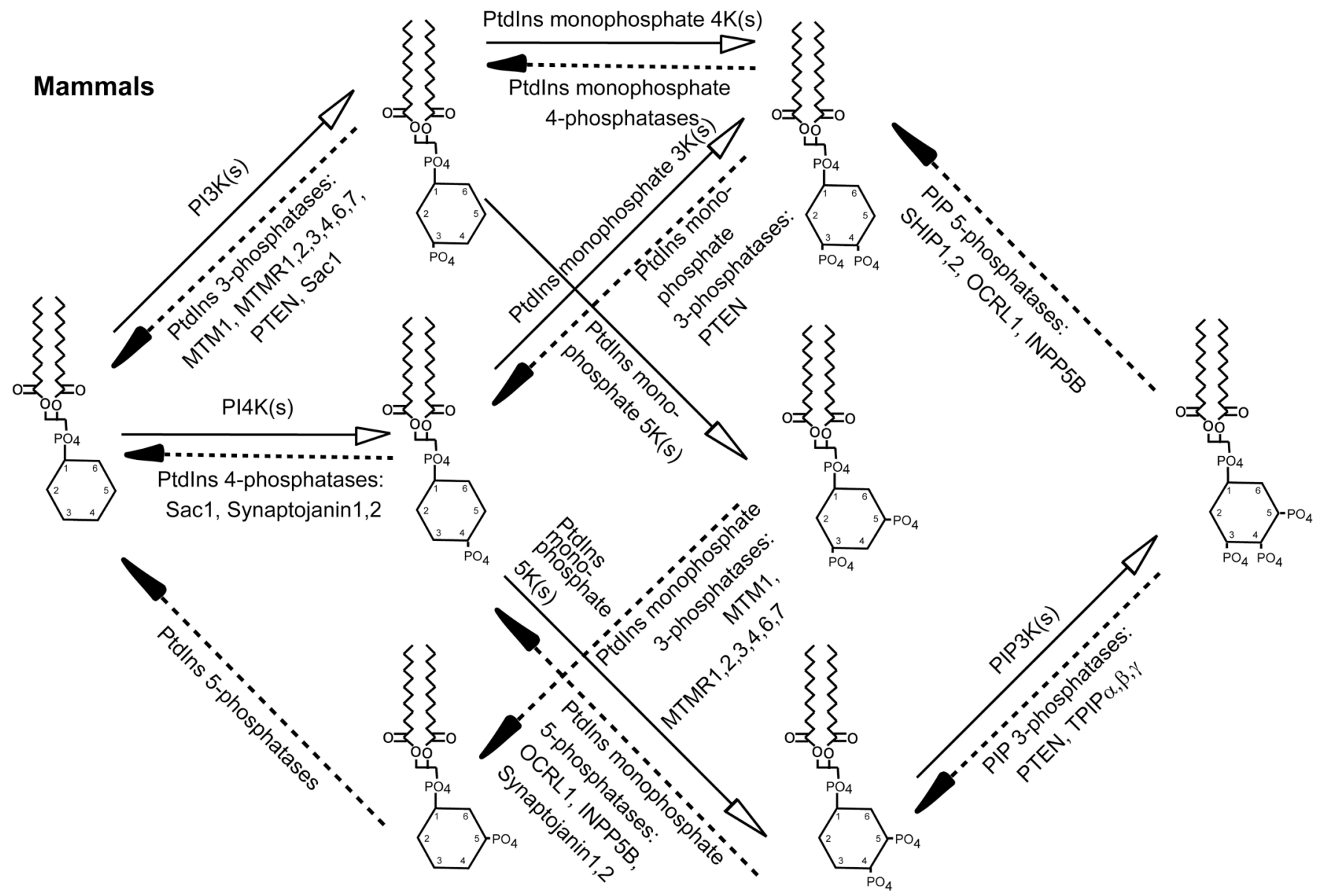

Figure 3.

Phosphoinositide metabolism in mammalian cells. The execution points of the mammalian PtdIns kinases and phosphoinositide phosphatases that regulate the synthesis and turnover of Phosphoinositides, respectively, are identified. 
A

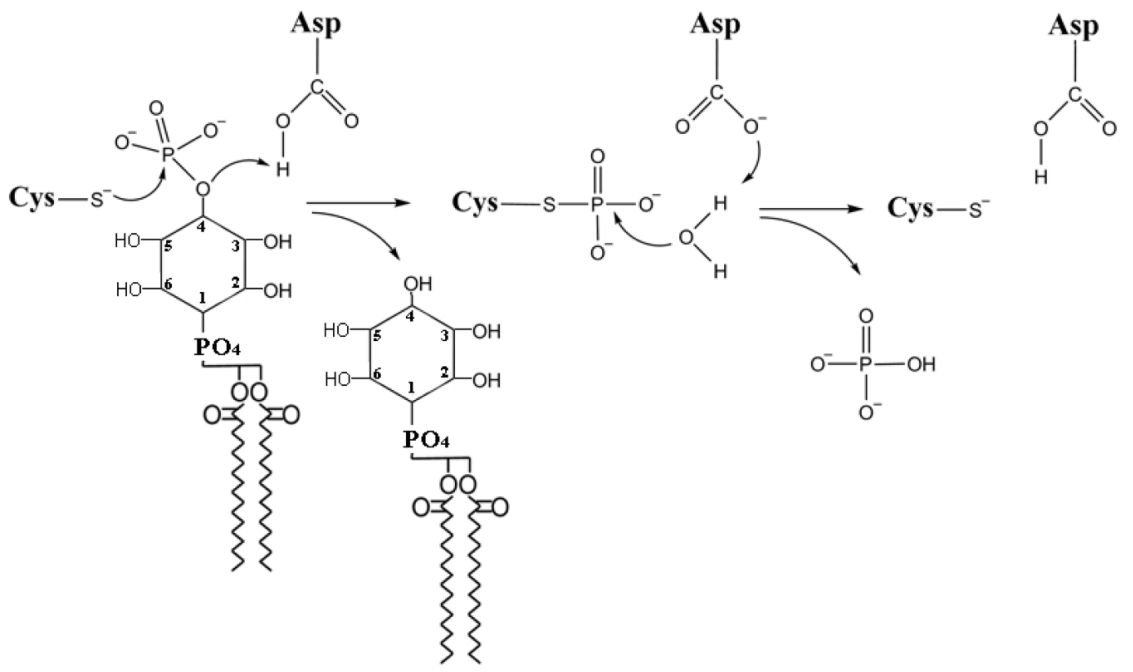

B

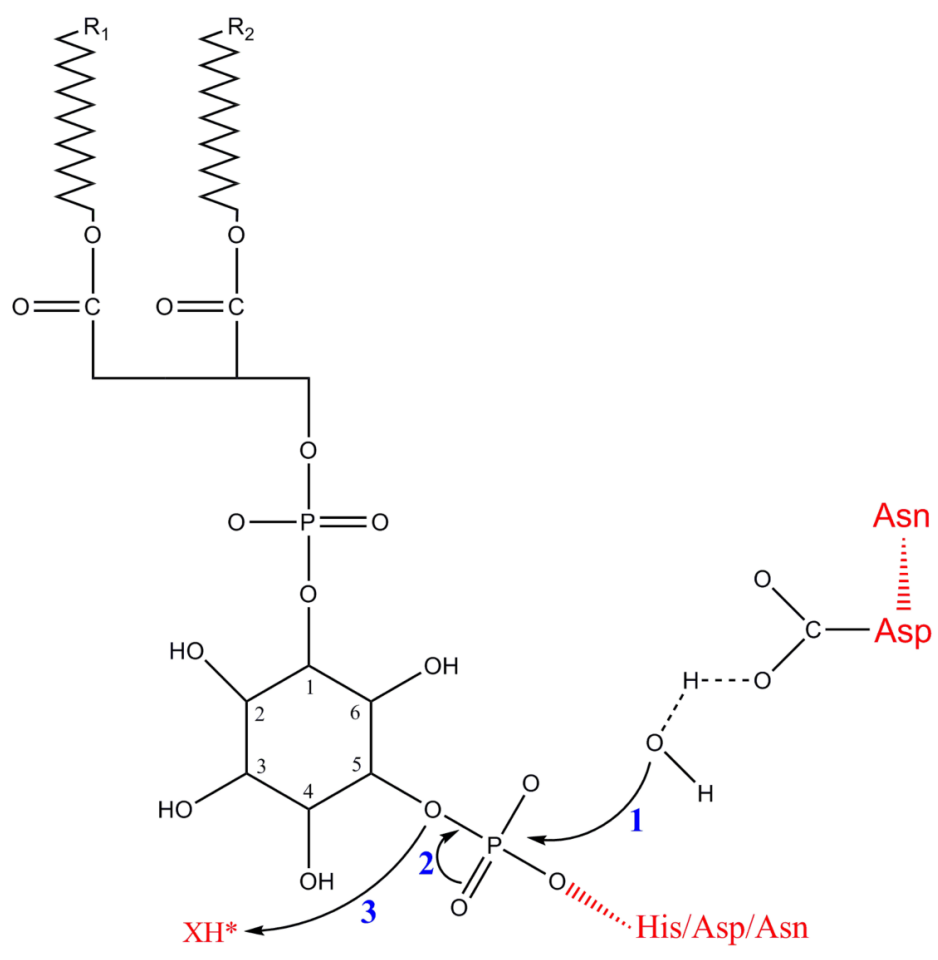

Figure 4.

Catalytic mechanisms of phosphoinositide phosphatases. (A) The $\mathrm{CX}_{5} \mathrm{R}(\mathrm{T} / \mathrm{S})$ phosphoinositide phosphatases of the PTP superfamily. These enzymes catalyze a doubledisplacement reaction where the leaving group alcohol is displaced by an active-site nucleophile. The resulting phospho-enzyme intermediate is resolved by transfer of the $\mathrm{PO}_{3}$ group to an acceptor water molecule. An aspartic acid subsequently donates a proton to the leaving-group oxygen to regenerate an uncharged hydroxy group at the position from which the $\mathrm{PO}_{3}$ group was displaced (Guan and Dixon, 1991; Fauman and Saper, 1996; Hughes et al., 2000a). (B) The inositol polyphosphate 5'-phosphatases of the AP endonuclease superfamily. These enzymes catalyze a displacement reaction where the leaving group alcohol 
is displaced by an actived water molecule as nucleophile. An invariant Asp residue, held in properly position by H-bonding with a conserved Asn, activates the nucleophilic water (1). A His/Asp pair cooperates with an invariant Asn to position the target phosphate bond for hydrolysis. $\mathrm{Mg}^{2+}$ is thought to stabilize a transition state in the reaction. There is no phosphoenzyme intermediate in this catalytic mechanism as the $\mathrm{PO}_{3}$ group is transferred directly to the nucleophilic water molecule (2). Either water, or some other functional group of the enzyme (both possibilities generically designated as $\mathrm{XH}^{*} ; \mathbf{3}$ ), donates a proton to the leaving-group oxygen to regenerate an uncharged hydroxyl group at the position from which the $\mathrm{PO}_{3}$ group was displaced. 


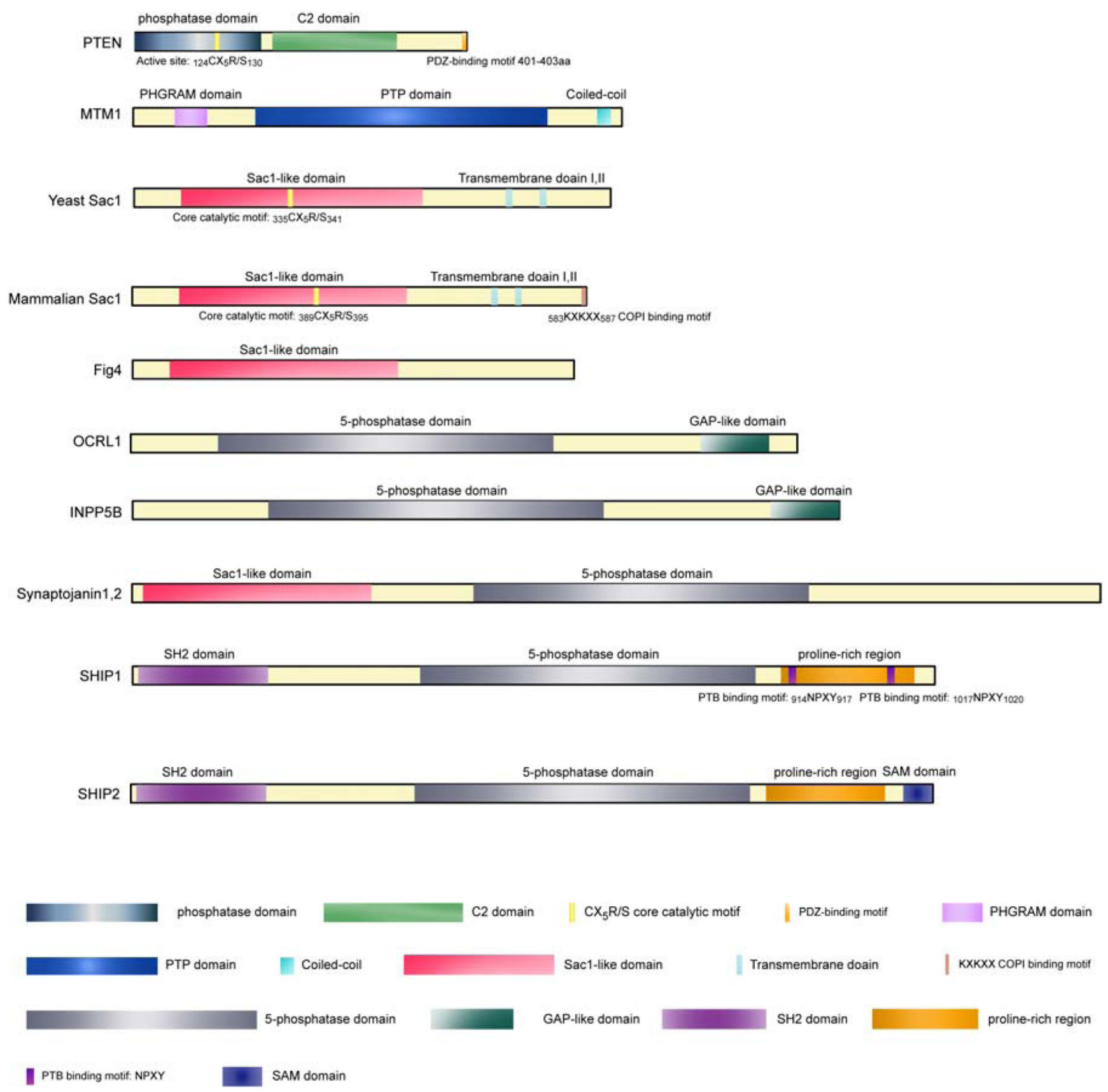

Figure 5.

Domain organization of phosphoinositide phosphatases. The domain structures of PTEN, MTM1, Sac1, Fig4, OCRL1, INPP5B, Synaptojanin 1,2, and SHIP1,2 are illustrated. Relevant functional domains and motifs are indicated. 


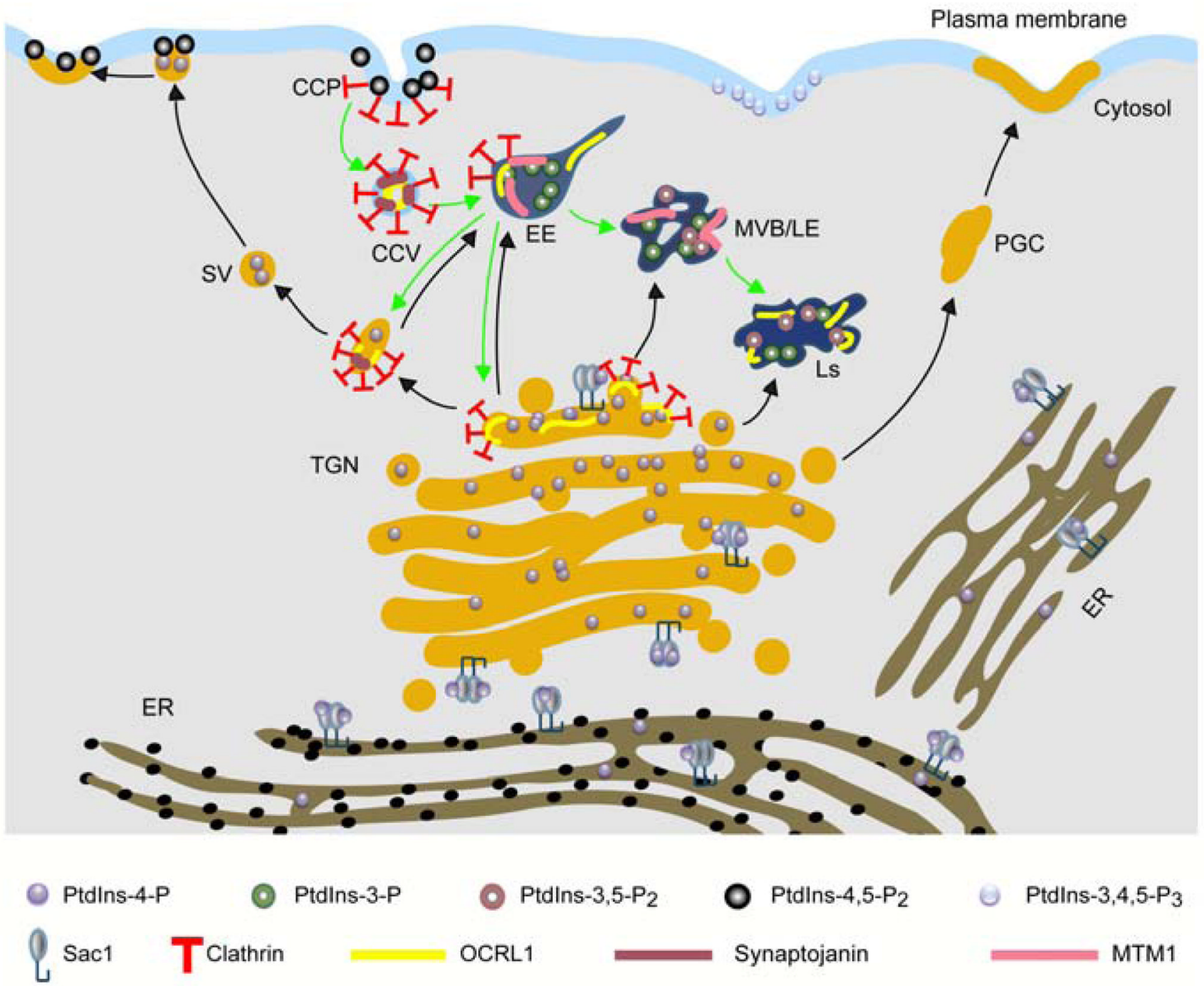

\section{Clathrin coated pit: CCP Clathrin coated vesicle: CCV Early endosome: EE Endoplasmic reticulum: ER}

\section{Lysosome: Ls Multivesicular body/Late endosome: MVB/LB Post Golgi carrier: PGC Secretory vesicle: SV}

\section{Trans-Golgi network: TGN}

Figure 6.

Phosphoinositide phosphatases and regulation of membrane trafficking. The phosphoinositide 4-phosphatase Sac1 is localized primarily in ER and Golgi membranes. OCRL1 (yellow) is localized to the Golgi/endosomal system and is a cargo of the clathrin-coated vesicles (CCVs) responsible for bidirectional membrane trafficking between TGN and endosomes. In the neuronal presynaptic plasma membrane, a PtdIns- 4,5- $\mathrm{P}_{2}$ pool is accessed by synaptojanin 1 during CCV uncoating. In non-neuronal cells, synaptojanin 2 (maroon) functions at an early stage of clathrin-mediated endocytosis. MTM1 (pink) regulates endocytic traffic and PTEN (red) degrades a PtdIns-3,4,5- $\mathrm{P}_{3}$ pool involved in membrane trafficking events associated with phagocytosis. Abbreviations: $\mathrm{CCP}$, clathrin-coated pit; $\mathrm{CCV}$, clathrin-coated vesicle; EE, early endosome; ER, endoplasmic reticulum; Ly, lysosome; MVB/LE, multivesicular body/late endosome; PGC, post-Golgi carrier; SV, secretory vesicle; TGN, trans-Golgi network. 
A

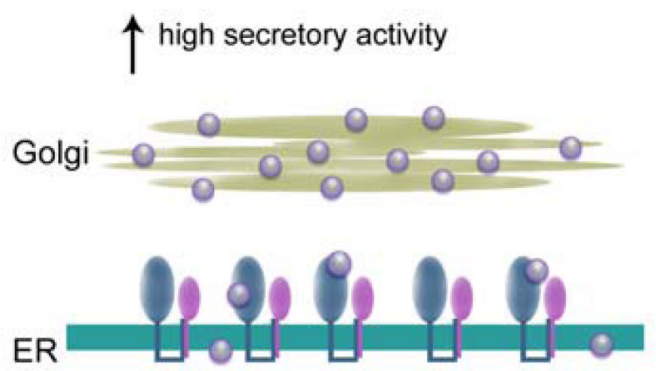

yeast cells under exponential growth

C

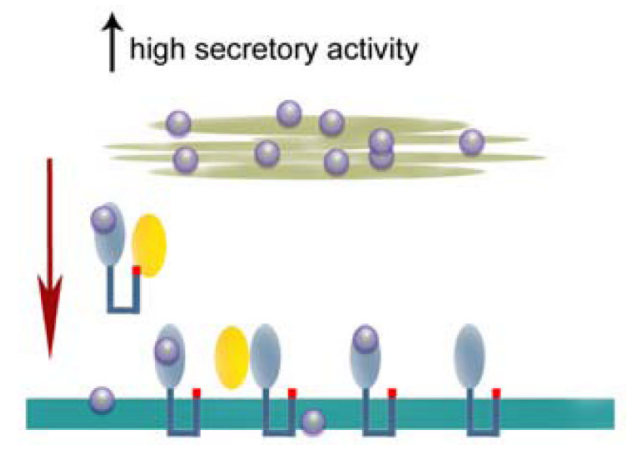

growth factor stimulated mammalian cell
B
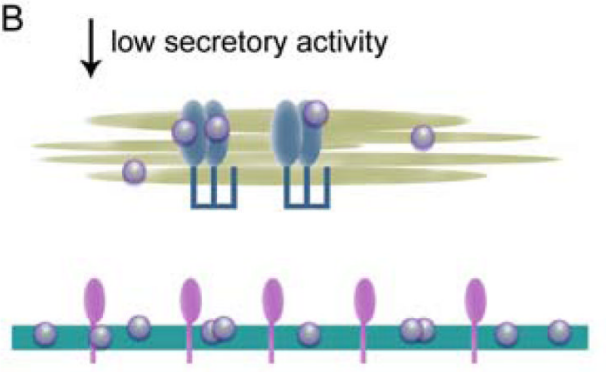

Џ ySac1

Ptdlns-4-P

yeast cells in limited nutrient condition

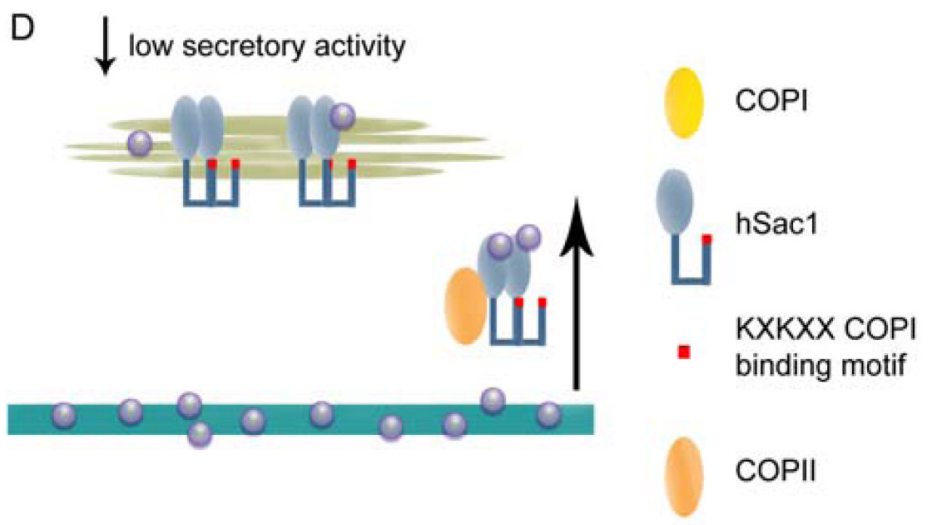

quiescent mammalian cell

Figure 7.

Dynamic regulation of Sac1 localization in yeast and mammals. When yeast cells are in exponential growth, the ER dolicholphosphate mannose synthase Dpm1p interacts with yeast Sac1 (ySac1) via their respective trans-membrane domains. This interaction restricts Sac1 to the ER, results in elevated Golgi PtdIns-4-P, and promotes robust secretory activity (A). Upon nutrient limitation, the ySac1 interaction with Dpm1p is broken and ySac1 escapes to Golgi membranes. Increased Golgi ySac1 reduces PtdIns-4-P levels and, subsequently, secretory activity (B). In mammalian cells, growth factor signaling promotes retrograde transport of Sac1 from Golgi membranes to the ER via an ARF- and COPI-dependent pathway. Consequent elevation of Golgi PtdIns-4-P promotes optimal secretion (C). In quiescent cells, Sac1 oligomerizes and translocates to the Golgi via a COPII-mediated pathway. Increased Golgi Sac1 reduces PtdIn-4-P pools and downregulates secretory activity (D). 